\title{
Structural Damage Detection Using Nonlinear Vibrations
}

\author{
M. Carminati $(\mathbb{D})$ and S. Ricci $(1 D)$ \\ Department of Aerospace Science and Technology, Politecnico di Milano, Via La Masa 34, 20156 Milano, Italy \\ Correspondence should be addressed to S. Ricci; sergio.ricci@polimi.it
}

Received 2 January 2018; Revised 17 June 2018; Accepted 16 July 2018; Published 25 September 2018

Academic Editor: Linda L. Vahala

Copyright (C) 2018 M. Carminati and S. Ricci. This is an open access article distributed under the Creative Commons Attribution License, which permits unrestricted use, distribution, and reproduction in any medium, provided the original work is properly cited.

\begin{abstract}
Nonlinear vibrations emerging from damaged structures are suitable indicators for detecting defects. When a crack arises, its behavior could be approximated like a bilinear stiffness. According to this scheme, typical nonlinear phenomena as the presence of superharmonics in the dynamic response and the variation of the oscillation frequency in time emerge. These physical consequences give the opportunity to study damage detection procedures with relevant improvements with respect to the typical strategies based on linear vibrations, such as high sensitivity to small damages, no need for an accurate comparison model, and behavior not influenced by environmental conditions. This paper presents a methodology, which aims at finding suitable nonlinear phenomena for the damage detection of three contact-type damages in a panel representing a typical aeronautical structural component. At first, structural simulations are executed using MSC Nastran models and reduced dynamic models in MATLAB in order to highlight relevant nonlinear behaviors. Then, proper experimental tests are developed in order to look for the nonlinear phenomena identified: presence of superharmonics in the dynamic response and nonlinear behavior of the lower frequency of vibration, computed using the CWT (continuous wavelet transform). The proposed approach exhibits the possibility to detect and localize contact-type damages present in a realistic assembled structure.
\end{abstract}

\section{Introduction}

In the actual aeronautical field, the damage detection methodologies are achieving a significant importance due to their great influence on both safety and cost/time optimization. Traditional maintenance schemes based on statistical predictions of times between controls are not optimal for cost savings. Moreover, maintenance implies two kinds of costs for operators [1]: direct costs (repairs) and indirect costs (stop imposed to the airplanes). Both of them are becoming excessive due to the augmentation of the operational life of several airplanes. Indeed, the probability for airplanes to suffer from unpredicted flight loads increases with that, forcing the trend of maintenance costs to grow. These aspects justify the interest in new inspection methodologies able to detect cracks and defects but at the same time guaranteeing time and cost reductions.

The traditional approaches to damage detection are represented by the NDT (nondestructive testing) techniques. They are off-line and localized inspections, developed since the early to mid of 1960s, mainly related to visual inspections, ultrasonic inspections, eddy currents, acoustic emissions, radiography, thermography, and shearography $[2,3]$. For the goals before highlighted, the interest has recently switched to structural health monitoring (SHM) schemes. They are online and global procedures, based on the idea of directly applying a system of detection giving the following benefits: absence of accessibility requirements for operating the tests, absence of necessity to predict possible collocations of damages before executing the trials, and a single time session for tests. SHM methods are classified as follows [4]: "modal-based methods," characterised by the comparison between modal parameters of the current structure with those of the undamaged one; "response-based methods," characterised by the analyses of the results to proper dynamic tests; and "model-based methods," characterised by the comparisons of results from experimental tests with those ones from numerical simulations.

The typical SHM methods are the linear vibrational schemes $[5,6]$, developed from the hypotheses of linear, time-independent structures. Among them, there has been a wide research on modal techniques since the 1970s [7]. 
These ones are based on the idea that a damage causes a reduction of the local physical stiffness, causing the modification of modal parameters (eigenfrequencies, damping ratios, and eigenvectors). Therefore, the comparison between these physical elements in the current state and in the undamaged one is suitable for detecting damages. These methodologies exhibit some weaknesses. At first, the traditional linear eigenfrequencies analyses are weakly sensitive to small damages. According to [8], a crack owning an area 15-20\% of the cross section of a beam structure determines a reduction of the natural frequency of the element from $1 \%$ to $5 \%$. This aspect is the consequence of the global character of modal methods, and thus it can be overpassed by augmenting the amount of data to analyze. In this scenario, the actual research is exhibiting interests in data mining (DM) techniques, such as the artificial neural networks (ANN), principal component analysis (PCA) [9], and genetic algorithms (GA), able to reduce the amount of data to be processed for SHM. Reference [10] represents a very recent review paper that includes a large and complete bibliography of papers about DM in structural damage detection. Then, traditional linear analyses are influenced by external conditions as temperature, which drive modal parameters to change. Finally, traditional linear analyses require accurate pieces of information on the undamaged structure as they focus on a comparison. This aspect implies the necessity for proper undamaged models or test results on the undamaged structures.

Nonlinear vibrational methods in SHM context are emerging in order to overcome the previous limitations. The basic idea around them is that a damage causes a nonlinear behaviour in the structure where it grows. For this reason, it is sufficient to detect the nonlinearities in order to state elements on the defect presence. According to [11], a simple but realistic way to represent the mechanical behaviour of a damage is the usage of a bilinear stiffness: when the crack is open, no material can locally sustain loads and thus a stiffness reduction happens; when it is closed, the originally undamaged stiffness is restored. This model justifies several nonlinear phenomena in vibrations that have been used in some research studies available in literature: absence of homogeneity [12], variation of frequency with amplitude of vibration [11], superharmonic generation [8, 11], and sum/difference of the input harmonics in the dynamic response [13]. The potential of nonlinear vibrational methods is related to their benefits: sensitivity to small defects, making them appealing in the assessment of damages at the very early moments of the growing process; absence of comparing models, influencing the time for the analyses; and insensitivity to environmental conditions, remarkable in the aeronautical context. According to these benefits, the research has concentrated on analytical/numerical modeled structures, with breathing cracks inside. The current paper presents an extension of these methods in a structure reproducing an aeronautical stiffened panel, in which three different damaged scenarios have been taken into account. Each defect is represented by the absence of connections between a portion of a stiffener and a base plate. The procedure aims at executing the first two steps of the detection procedure scheduled by Rytter in [14]: detection and localization, leaving the damage quantification step for the next research phase.

\section{Theoretical Background}

In order to justify the phenomena emerging from nonlinearities suitable for the damage detection procedure here discussed, a short theoretical background on nonlinear systems is mandatory.

2.1. Nonlinear Phenomena. A nonlinear dynamical system owns particular characteristics compared to those of the linear processes. Firstly, the dynamical response to an input excitation depends both on the frequency of the excitation and its amplitude. For a linear system, instead, the only dependence is that from the excitation frequency. Then, nonlinear systems exhibit sensitivity to initial conditions. In the case of linear time-invariant systems, the impulse response is the linear combination of specific shapes, called eigenvectors, vibrating at specific eigenfrequencies. These invariant sets do not depend on initial conditions. Moreover, given a certain group of harmonics in the input signal, the output of a nonlinear system may present subharmonics or superharmonics. Finally, due to the high sensitivity to initial conditions, nonlinear systems can exhibit a chaotic behavior also with deterministic nonlinear models.

The mathematician Volterra proposed an extension of the conventional input-output relation used to describe dynamical systems in the time domain [15]. For a linear time-invariant system, the output $\mathbf{y}(t)$ is related to the input $\mathbf{u}(t)$ by the following convolution:

$$
\mathbf{y}(t)=\int_{-\infty}^{+\infty} \mathbf{h}(\tau) \mathbf{u}(t-\tau) d \tau
$$

where $\mathbf{h}(t)$ is the impulse response of the system. The form of the relation for nonlinear systems becomes the Volterra series:

$$
\mathbf{y}(t)=\sum_{i=1}^{n} \mathbf{y}_{i}(t)
$$

where

$$
\begin{aligned}
\mathbf{y}_{n}(t)= & \int_{-\infty}^{+\infty} \int_{-\infty}^{+\infty} \ldots \int_{-\infty}^{+\infty} \mathbf{h}_{n}\left(\tau_{1}, \tau_{2}, \ldots, \tau_{n}\right) \mathbf{u}\left(t-\tau_{1}\right) \mathbf{u} \\
& \cdot\left(t-\tau_{2}\right) \ldots \mathbf{u}\left(t-\tau_{n}\right) d \tau_{1} d \tau_{2} \ldots d \tau_{n}
\end{aligned}
$$

The terms $\mathbf{h}_{i}(t)$ are called "kernels." This relation is correct under specific hypothesis [16], always included in "weakly" nonlinear systems. Each kernel can be transformed into the frequency domain by using the multidimensional Fourier transform (MFT):

$$
\begin{aligned}
\mathbf{H}_{n}\left(\omega_{1}, \omega_{2}, \ldots, \omega_{n}\right)= & \int_{-\infty}^{+\infty} \int_{-\infty}^{+\infty} \ldots \int_{-\infty}^{+\infty} \mathbf{h}_{n} \\
& \cdot\left(\tau_{1}, \tau_{2}, \ldots, \tau_{n}\right) \mathbf{e}^{-i\left(\omega_{1} \tau_{1}+\omega_{2} \tau_{2}+\cdots+\omega_{n} \tau_{n}\right)} d \tau_{1} d \tau_{2} \ldots d \tau_{n} .
\end{aligned}
$$




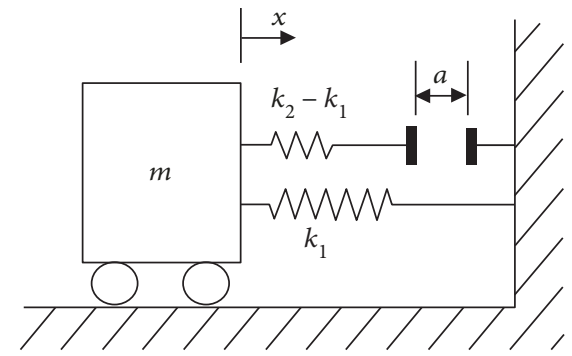

Figure 1: 1 dof system with bilinear spring.

The terms $\mathbf{H}_{n}$ are the higher-order frequency response functions (HOFRF). It can be easily noticed how the Volterra series including only its first term corresponds to (1). Thus, the input-output relation for linear systems is a particular case of (2). The MFT of the single kernel is the Fourier transform (FT) of the impulse response, which represents the frequency response function (frf) for asymptotically stable linear systems.

The Volterra series can be used in order to justify the superharmonic presence in the output of nonlinear systems. Indeed, in the case of a periodic excitation composed by the harmonic $\omega\left(u(t)=e^{i \omega t}\right)$, the expression of the response $y(t)$ is the following one:

$y(t)=H_{1}(\omega) e^{i \omega t}+H_{2}(\omega, \omega) e^{i 2 \omega t}+\cdots+H_{n}(\omega, \omega, \ldots, \omega) e^{i n \omega t}$.

The response exhibits multiple integers of the harmonic $\omega$ through the effect of the HOFRF. It is possible to match the values of each HOFRF to the Fourier transform of the input and the output [17].

Another relevant aspect described by the Volterra series is the absence of homogeneity. While each single convolution of the series is homogeneous, the response is the combination of homogeneous convolutions with different numbers of input functions. Consequently, differences in the amplitude of the input cause a nonhomogeneous system response.

2.2. A Simple 1 Degree of Freedom Example. In order to highlight the two effects underlined at the end of the previous paragraph for nonlinear systems and relate them to a bilinear spring mechanism representing a damage, it is here proposed a simple 1 degree of freedom (dof) example coming from the work of Neild [11]. Figure 1 represents a mass $m$ linked to the wall by a bilinear spring: the spring constant is $k_{1}$ until the displacement $x$ is less than $a$; then, it becomes $k_{2}$. Distance $a$ in the model can be both considered as a crack opening size or a contact gap. The first representation is that of a "breathing crack," as indicated in [11]. The second one suits with the contact-type damages analyzed in the work here presented.

The equations of motion for the two different situations are here proposed:

$$
\begin{aligned}
m \ddot{x}+k_{1} x=0, & \text { if } x \leq \mathrm{a}, \\
m \ddot{x}+k_{2} x+\left(k_{1}-k_{2}\right) a=0, & \text { if } x>a .
\end{aligned}
$$

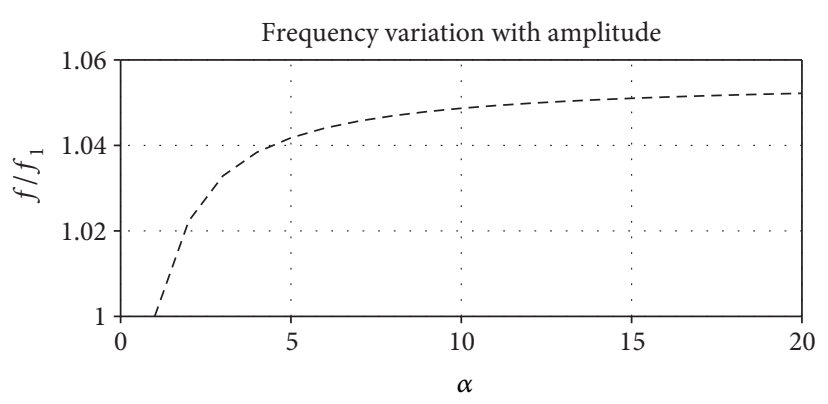

FIgURE 2: Normalized frequency with different amplitudes.

The solutions of the equations for the two cases can be easily found once the initial conditions are defined. Considering the motion evolving from an initial position $x(0)=-\alpha a$, with an initial speed equal to zero, the following equation expresses the motion behaviour:

$$
x=C \cos \left(\sqrt{\frac{k}{m}} t+\varphi\right)-\frac{K}{k} t,
$$

where $k=k_{1}$ and $K=0$ when $x \leq a$ and $k=k_{2}$ and $K=$ $\left(k_{1}-\mathrm{k}_{2}\right) a$ when $x>a$. Constants $C$ equals $-\alpha a$ and constant $\varphi$ equals 0 in the first case. When $x>a$, their values are the following ones:

$$
\begin{aligned}
& C=a \frac{k_{1}}{k_{2}} \sqrt{1+\frac{k_{2}}{k_{1}}\left(\alpha^{2}-1\right)}, \\
& \varphi=\arctan \left(-\sqrt{\frac{k_{2}}{k_{1}}\left(\alpha^{2}-1\right)}\right) .
\end{aligned}
$$

Through the analytic calculation of [11], the nondimensional $f_{s}=f /\left(\omega_{1} / 2 \pi\right)$ can be computed, where $\omega_{1}=\sqrt{k_{1} / m}$ and $f$ equals the frequency of oscillation. Once the mathematical model is solved, it is possible to determine the nondimensional frequency of vibration for different values of $\alpha$ (Figure 2). Moreover, it is possible to highlight the second and third normalized superharmonics by applying the fast Fourier transform (FFT) to the normalized displacement stories. They are equal to their value divided by $f_{1}=\omega_{1} / 2 \pi$ (Figure 3 ).

The results clearly underline the consequences of the bilinear spring in the system response. Figure 2 shows how the vibration frequency depends on the amplitude of the oscillation; Figure 3 underlines the presence of the superharmonics in the dynamic response.

\section{Typical Aeronautical Panel: Preliminary Numerical Studies}

The panel analyzed in the current work reproduces a typical aeronautical structure. It is the one used in $[9,18]$. It consists in a flat rectangular plate, having $1000 \mathrm{~mm}$ for width and $1200 \mathrm{~mm}$ for length, with a thickness of $1.3 \mathrm{~mm}$. It is edged by two transversal supports with rectangular section 


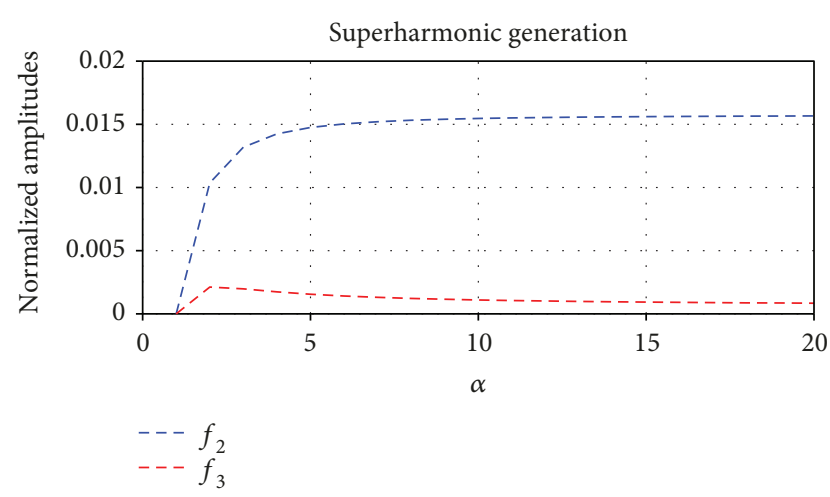

FIgURE 3: Normalized superharmonics with different amplitudes.

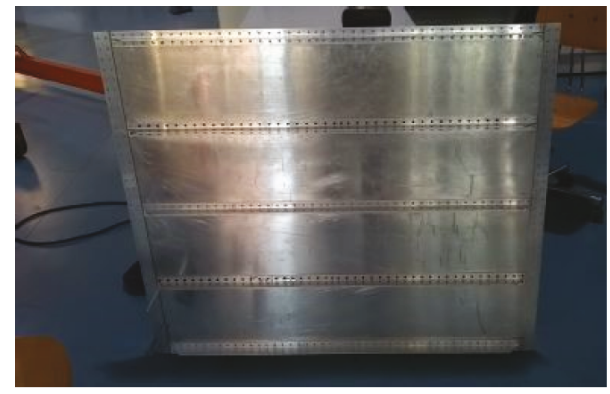

FIGURE 4: Aluminum panel used for the analyses.

TABLE 1: Damaged scenario characteristics.

\begin{tabular}{lc}
\hline Case & Description \\
\hline D2 & Separation, $80 \mathrm{~mm}$ long; ending stiffener position \\
D3 & Separation, $120 \mathrm{~mm}$ long; central stiffener position \\
D5 & Separation, $40 \mathrm{~mm}$ long; ending stiffener position \\
\hline
\end{tabular}

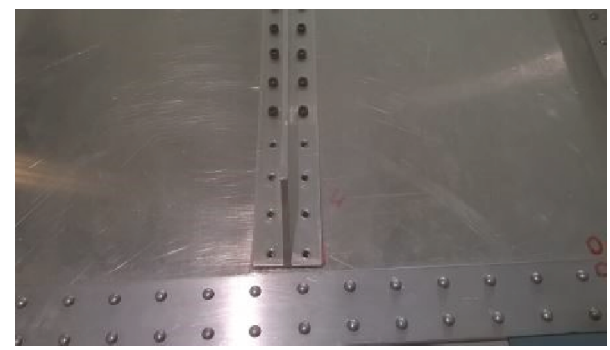

Figure 5: Detail of D2 damage.

$(40 \mathrm{~mm} \times 4 \mathrm{~mm})$, running along the short sides. Moreover, five stiffeners equally spaced reinforce the longitudinal direction: they are all T-shaped, with a length of $1120 \mathrm{~mm}$, a flange and a web of $40 \mathrm{~mm}$, and a constant thickness of $4 \mathrm{~mm}$. The whole panel is built using aluminum alloy 2024 . Figure 4 shows the panel.

The three damaged scenarios are represented by the absence of connections between one stiffener and the base plate (two lines of screws are used to connect each stiffener to the base plate). They are called D2, D3, and D5. Table 1 summarizes the characteristics of each one of them.

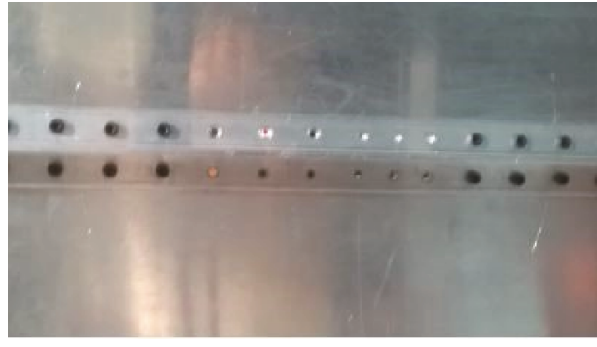

FIgURE 6: Detail of D3 damage.

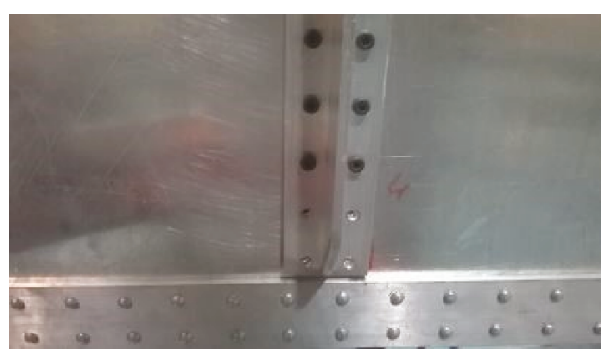

Figure 7: Detail of D5 damage.

TABLE 2: First 20 eigenfrequencies for the undamaged panel and for the three damages with their $\%$ variations.

\begin{tabular}{|c|c|c|c|c|c|c|c|}
\hline Mode & $f(\mathrm{~Hz})$ & $\begin{array}{c}\mathrm{D} 2, \\
f(\mathrm{~Hz})\end{array}$ & D2, \% & $\begin{array}{c}\text { D3, } \\
f(\mathrm{~Hz})\end{array}$ & D3, \% & $\begin{array}{c}\text { D5, } \\
f(\mathrm{~Hz})\end{array}$ & D5, $\%$ \\
\hline 1 & 7.95 & 7.79 & -2.01 & 7.95 & 0.00 & 7.83 & -1.51 \\
\hline 2 & 11.38 & 11.37 & -0.09 & 11.38 & 0.00 & 11.38 & 0.00 \\
\hline 3 & 23.67 & 23.44 & -0.97 & 23.67 & 0.00 & 23.51 & -0.68 \\
\hline 4 & 27.90 & 26.67 & -4.41 & 27.90 & 0.00 & 27.60 & -1.08 \\
\hline 5 & 47.72 & 43.15 & -9.58 & 47.72 & 0.00 & 46.56 & -2.43 \\
\hline 6 & 49.82 & 48.93 & -1.79 & 49.82 & 0.00 & 49.11 & -1.43 \\
\hline 7 & 72.67 & 71.01 & -2.28 & 72.58 & -0.12 & 71.47 & -1.65 \\
\hline 8 & 83.43 & 73.63 & -11.75 & 83.43 & 0.00 & 80.68 & -3.30 \\
\hline 9 & 87.70 & 85.73 & -2.25 & 87.57 & -0.15 & 86.44 & -1.44 \\
\hline- & - & 93.42 & - & - & - & - & - \\
\hline 10 & 99.22 & 99.41 & 0.19 & 98.89 & -0.33 & 98.20 & -1.03 \\
\hline 11 & 101.11 & 99.88 & -1.22 & 101.10 & -0.01 & 99.76 & -1.34 \\
\hline 12 & 101.22 & 109.68 & 8.36 & 100.97 & -0.25 & 100.20 & -1.01 \\
\hline 13 & 114.46 & 114.63 & 0.15 & 114.45 & -0.01 & 112.51 & -1.70 \\
\hline 14 & 117.42 & 117.48 & 0.05 & 115.53 & -1.61 & 116.92 & -0.43 \\
\hline 15 & 118.05 & 117.86 & -0.16 & 117.70 & -0.30 & 117.86 & -0.16 \\
\hline 16 & 121.78 & 121.75 & -0.02 & 121.77 & -0.01 & 121.75 & -0.02 \\
\hline 17 & 121.82 & 126.57 & 3.90 & 121.65 & -0.14 & 119.86 & -1.61 \\
\hline 18 & 128.90 & 131.10 & 1.71 & 128.88 & -0.02 & 128.15 & -0.58 \\
\hline 19 & 137.98 & 137.16 & -0.59 & 137.68 & -0.22 & 137.36 & -0.45 \\
\hline 20 & 139.43 & 139.27 & -0.11 & 139.34 & -0.06 & 139.33 & -0.07 \\
\hline
\end{tabular}

Figures 5-7 show the different cases.

Table 2 shows the first 20 eigenfrequencies of the undamaged free-free panel and exhibits the eigenfrequencies and their percentage variations for the three damaged cases considered. All the results have been obtained by means of numerical FEM mode analyses in MSC Nastran, by 


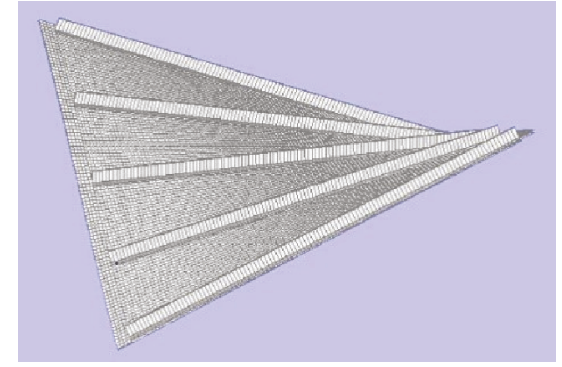

FIgURe 8: Mode 1.

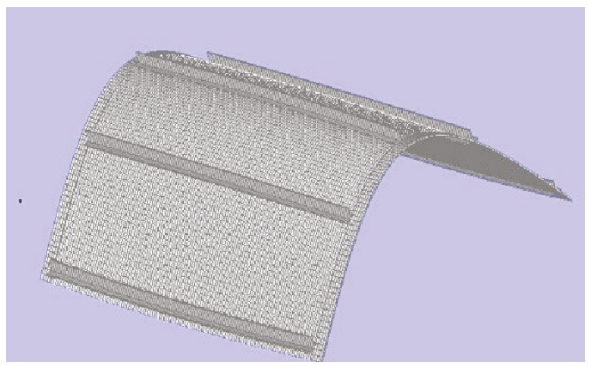

FIgURE 9: Mode 2.

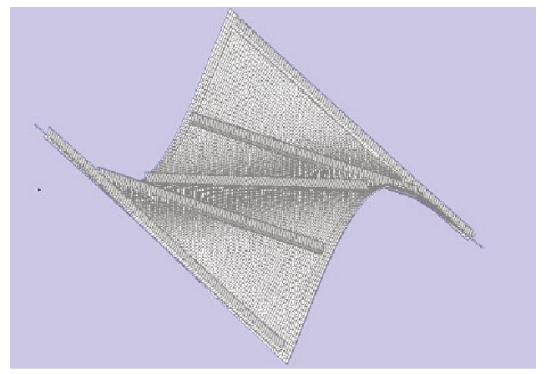

FIgURe 10: Mode 3.

representing each damaged area using not merged nodes between the damaged stiffener and the panel. In the case of D2, an uncorrelated mode at frequency $93.42 \mathrm{~Hz}$ has been identified.

Figures $8-13$ show the numerical shapes for the first six undamaged modes.

Figures 14-16 show the MAC (modal assurance criterion) matrixes obtained comparing the first undamaged 20 modes with the corresponding damaged ones.

Each MAC matrix has been obtained by comparing the transversal (out of plane) displacements of a set of 120 nodes equally spaced along the lateral and longitudinal directions of the panel.

Figure 14 clearly exhibits the not correlated mode at $93.42 \mathrm{~Hz}$ (mode number 10) emerging for D2, which interrupts the dominant behavior of the main diagonal of the matrix.

In order to highlight the presence of nonlinear phenomena, preliminary numerical tests have been run both using complete FEM (finite element method) models with the software MSC Nastran and reduced models with the

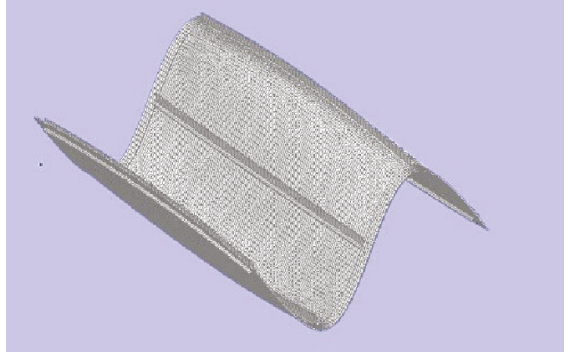

Figure 11: Mode 4.

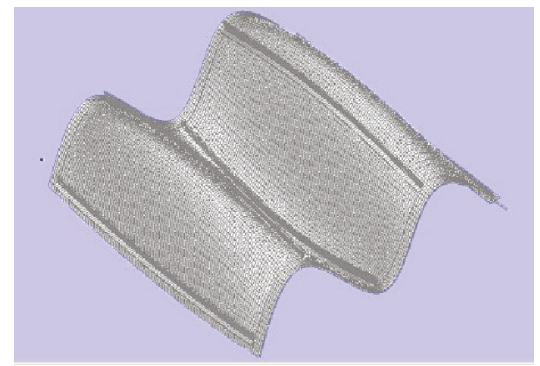

Figure 12: Mode 5.

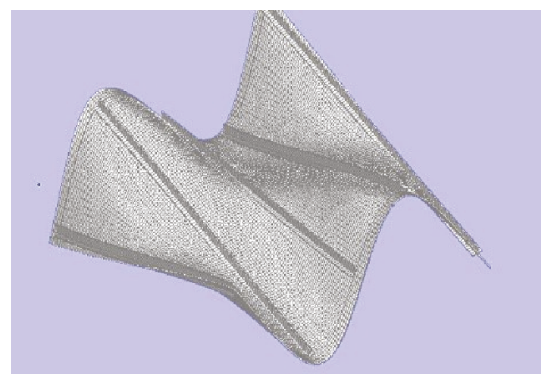

Figure 13: Mode 6.

software MATLAB. The panel has been analyzed as a freefree structure.

3.1. FEM Analyses on Complete Models. The original undamaged panel model has been developed in Nastran by using 12800 CQUAD4 elements (12000 for the base plate mesh, 800 for the transversal supports) and 560 CBEAM elements for the stiffeners. Each damaged scenario has been obtained from the original model by using a certain amount of GAP elements, connecting pairs of nodes in the vertical direction: they are nonlinear tools used to implement a bilinear stiffness. In particular, the penalty approach has been used in order to simulate the contact mechanism in each damaged area: when there is a contact between the two nodes connected by the gap, a stiffness of $10^{9} \mathrm{~N} / \mathrm{m}$ acts in order to avoid interpositions. The cards used to implement these gaps are CGAP and PGAP for the property definition [19].

For each scenario, a limited number of gap elements have been used only for the central pairs of nodes involved in 

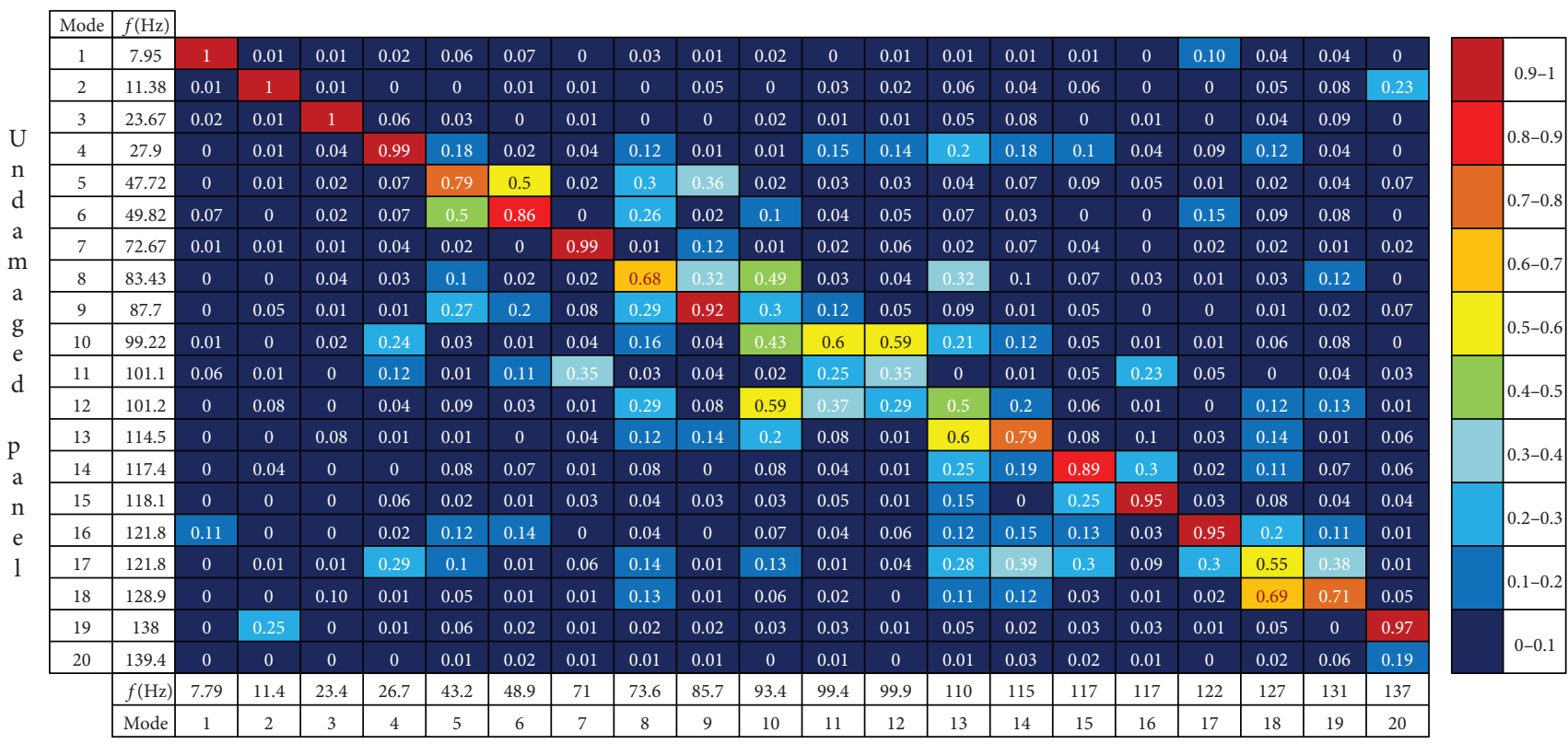

D2 damaged panel

FIGURE 14: Undamaged panel-D2 damaged panel MAC.

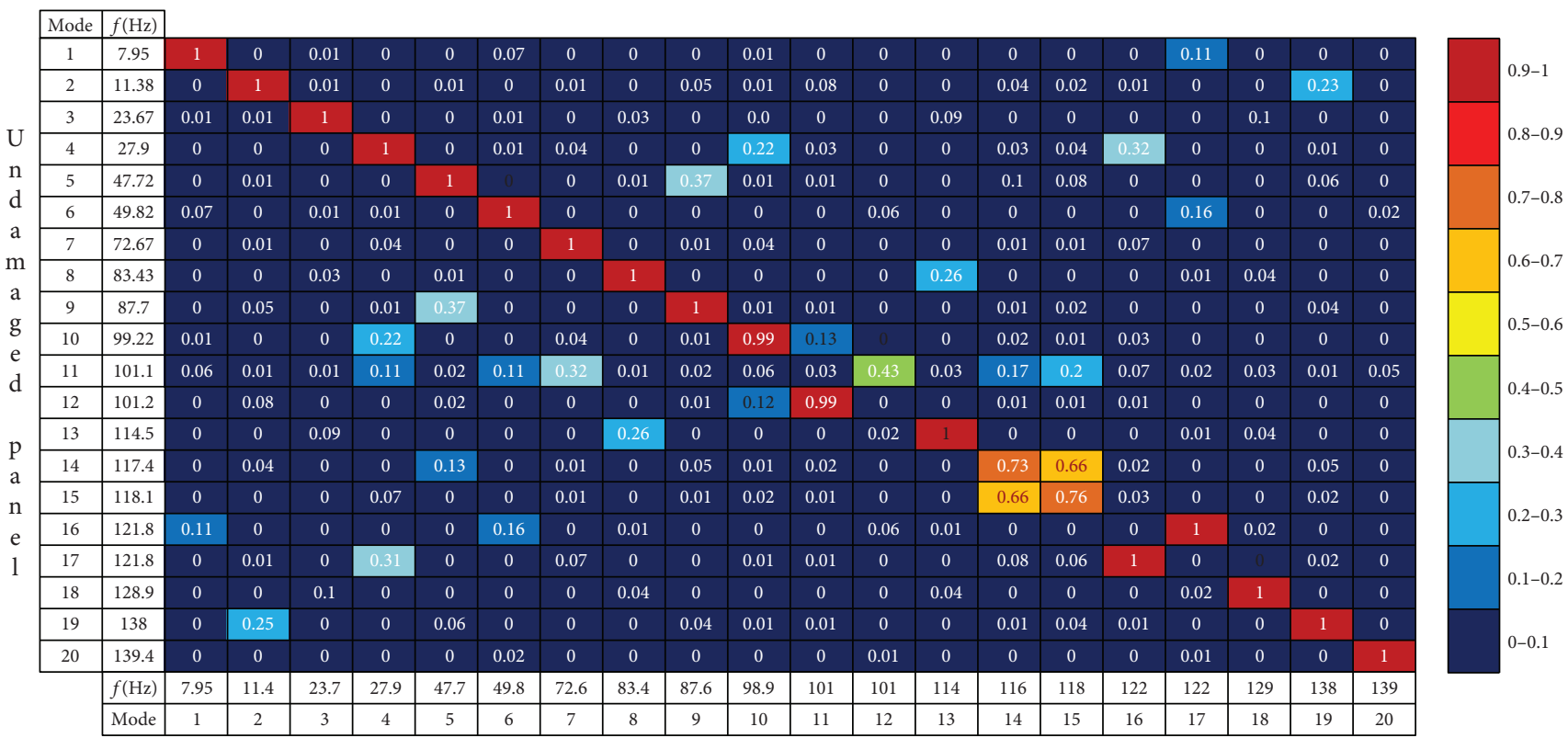

D3 damaged panel

FIGURE 15: Undamaged panel-D3 damaged panel MAC.

order to reduce the time required for the analyses with the SOL 129 ("nonlinear transient solution"): damages D2 and D3 present three gaps and damage D5 presents two gaps.

The campaign of FEM analyses with complete models has regarded the following tests:

(i) Double sine excitation tests: a $5 \mathrm{~Hz}$ vertical (out of plane) sinusoidal excitation and a $15 \mathrm{~Hz}$ one have been located on the opposite sides of the damaged stiffener, with amplitudes of $50 \mathrm{~N}$ and duration of $10 \mathrm{~s}$. Acceleration stories in the excited nodes and in the other three nodes along the damaged stiffener have been windowed with the Hanning window and finally analyzed by using the FFT (all the elaborations have been executed in MATLAB). Figures 17-19 show the locations of the exciting nodes (node 12 for $5 \mathrm{~Hz}$ excitation and node 93 for $15 \mathrm{~Hz}$ excitation) and the 


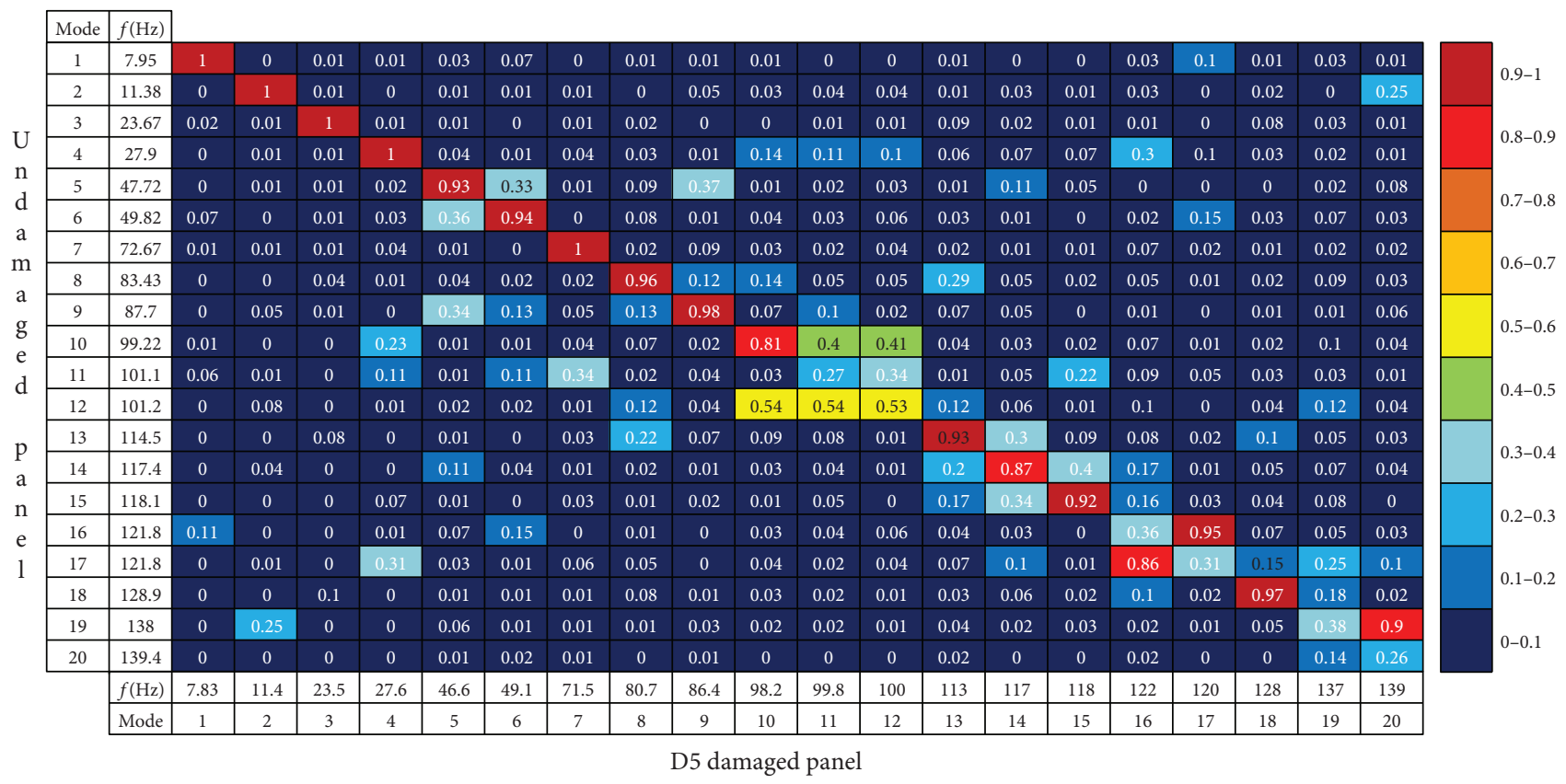

FIGURE 16: Undamaged panel-D5 damaged panel MAC.
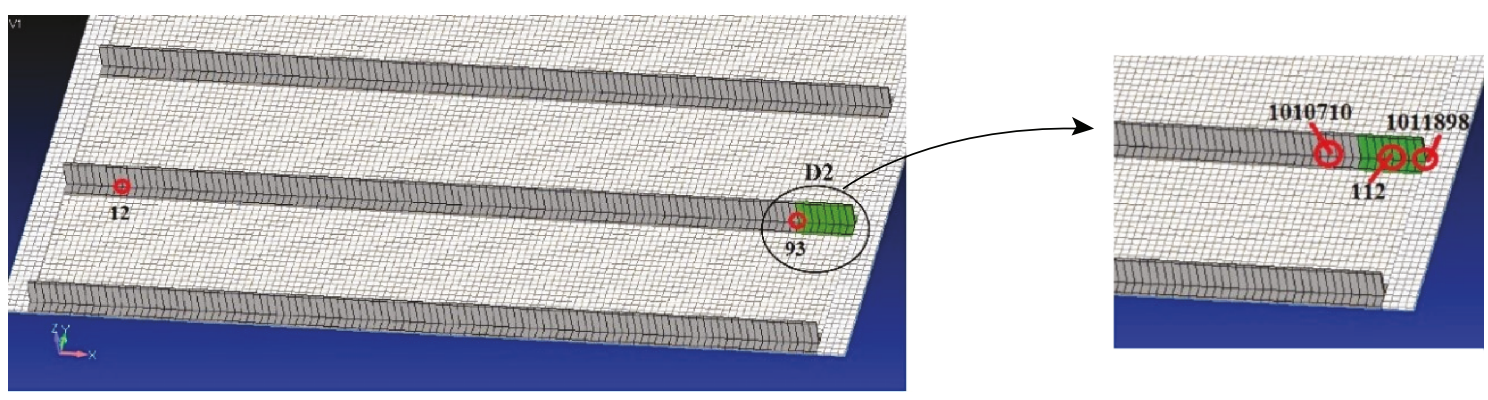

FIgURE 17: Excitation and measuring nodes for D2 damage along the second stiffener.
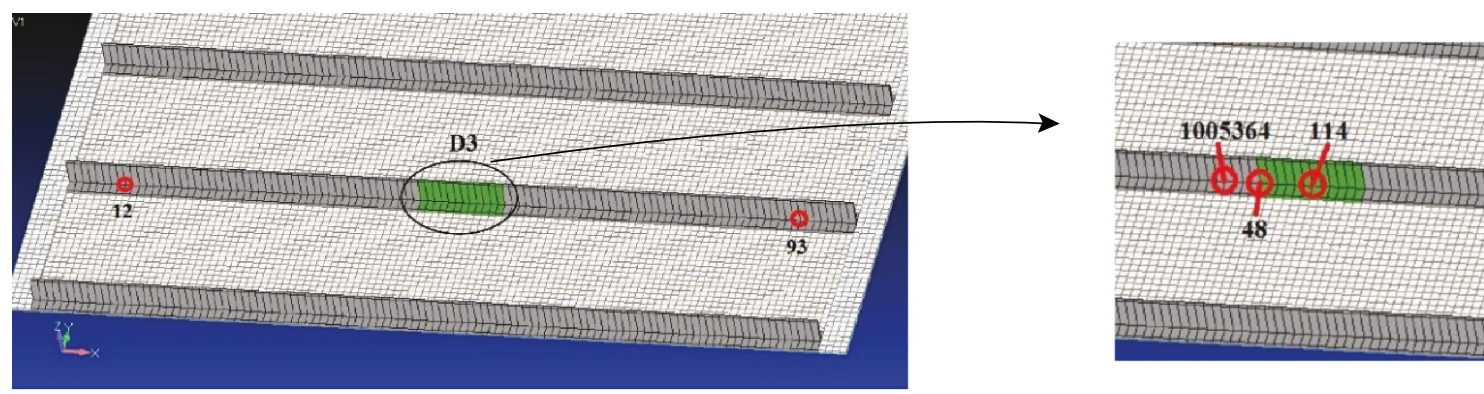

FIgURE 18: Excitation and measuring nodes for D3 damage along the second stiffener.

positions of the other three measuring nodes for each damage, along the second stiffener.

The double sine excitation at the indicated frequencies has been chosen in order to look for possible linear combinations, sum, or difference of the excitation frequencies in the outputs. The use of a difference between the two frequencies matching a structural eigenfrequency determines a relevant response, as indicated in the literature [13]. As a benefit of nonlinear methods is to provide detection without having preliminary pieces of information on the structure, it has been decided to consider $5 \mathrm{~Hz}$ and $15 \mathrm{H}$. They are low frequencies having a difference which does not meet a panel eigenfrequency.

In the case of the damaged scenario D2, a $30 \mathrm{~Hz}$ response in the results has been obtained. Figure 20 

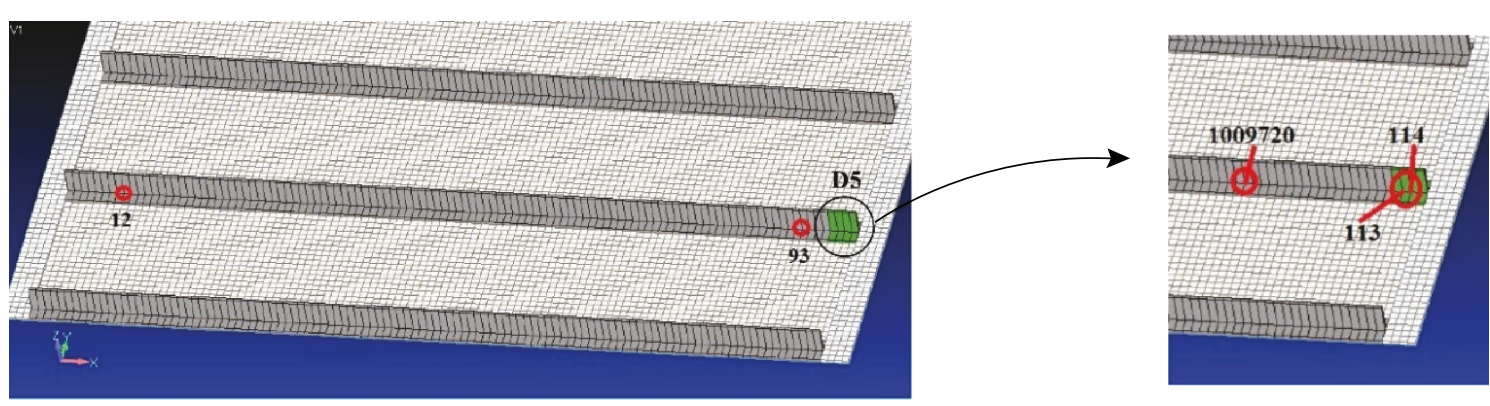

FIGURE 19: Excitation and measuring nodes for D5 damage along the second stiffener.

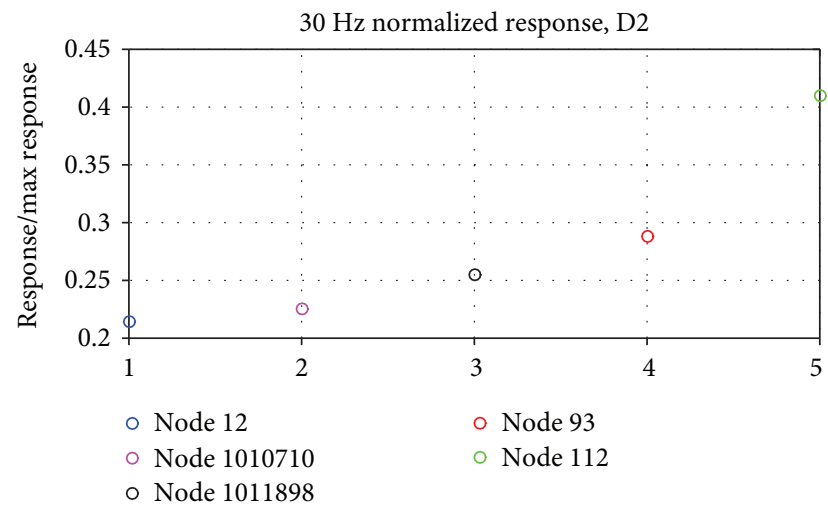

FIGURE 20: D2, $30 \mathrm{~Hz}$ normalized responses, double excitation tests.

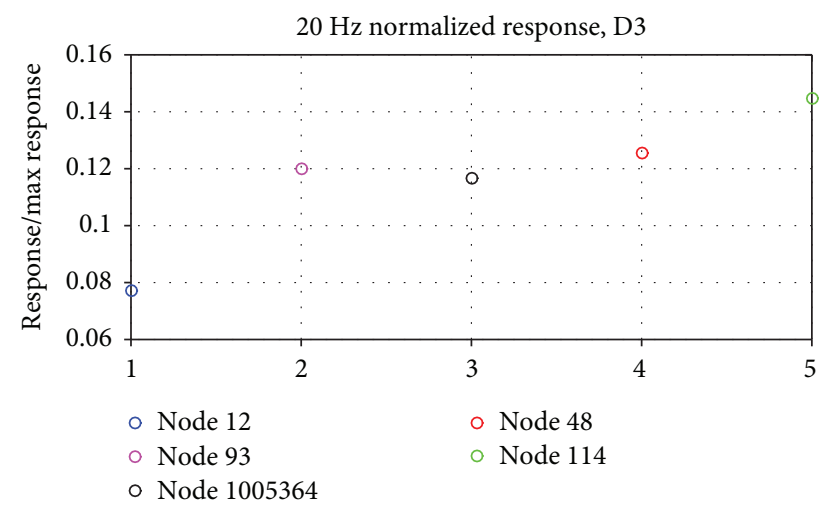

FIgURE 21: D3, $20 \mathrm{~Hz}$ normalized responses, double excitation tests.

reports the behavior of the normalized response for the different measurement points, obtained by dividing its value by the maximum one in the spectrum. In the figure, the nodes in the abscissa go closer to the damaged area from the left to the right. Thus, the amount of superharmonic contribution increases with the proximity to the damage. Similar results have been obtained for the $20 \mathrm{~Hz}$ contribution in the damaged scenario D3 (Figure 21) and for the $25 \mathrm{~Hz}$ contribution in each damaged scenario (Figures 22-24). These representations highlight the possibility to use the amount of the nonlinear response as an indicator for the localization.

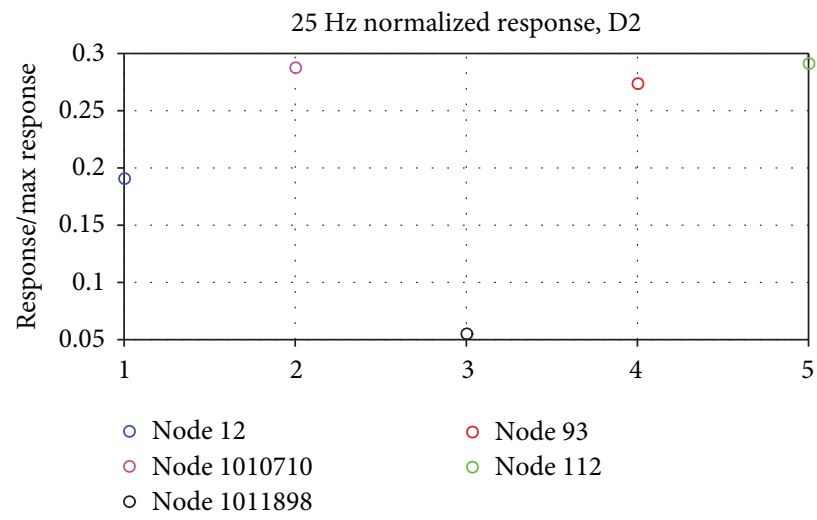

FIgURE 22: D2, $25 \mathrm{~Hz}$ normalized responses, double excitation tests.

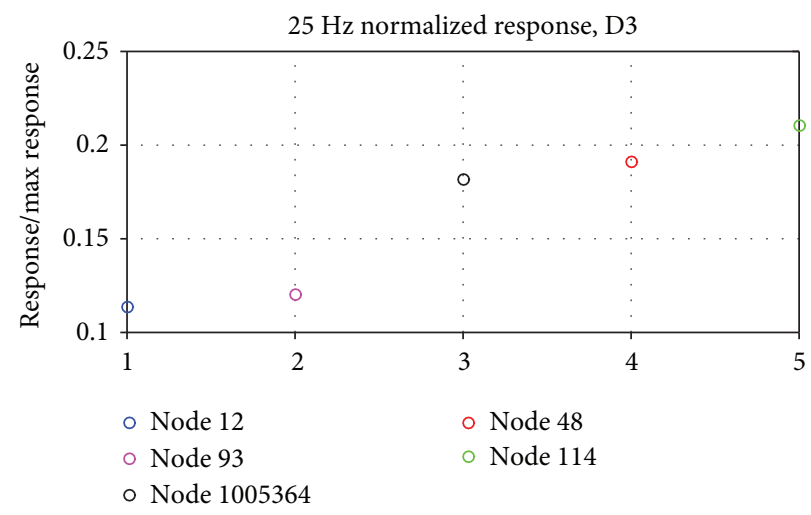

FIgURE 23: D3, $25 \mathrm{~Hz}$ normalized responses, double excitation tests.

(ii) Tests for superharmonics: for each damaged scenario, two different numerical tests have been executed applying a $50 \mathrm{~N}$ amplitude vertical sinusoidal force next to each damaged area. It has been decided to use the same frequencies of the previous tests, in order to highlight possible similarities in the results. Thus, in the first case, the frequency is $5 \mathrm{~Hz}$ and in the second case, it is $15 \mathrm{~Hz}$ for a duration of $12 \mathrm{~s}$. In the case of the $15 \mathrm{~Hz}$ excitation, scenario D2 has exhibited the superharmonic $30 \mathrm{~Hz}$ highlighted in the tests done before (Figure 25).

(iii) Decay tests: for each damaged scenario, an impulsive vertical load has been applied next to each damaged 


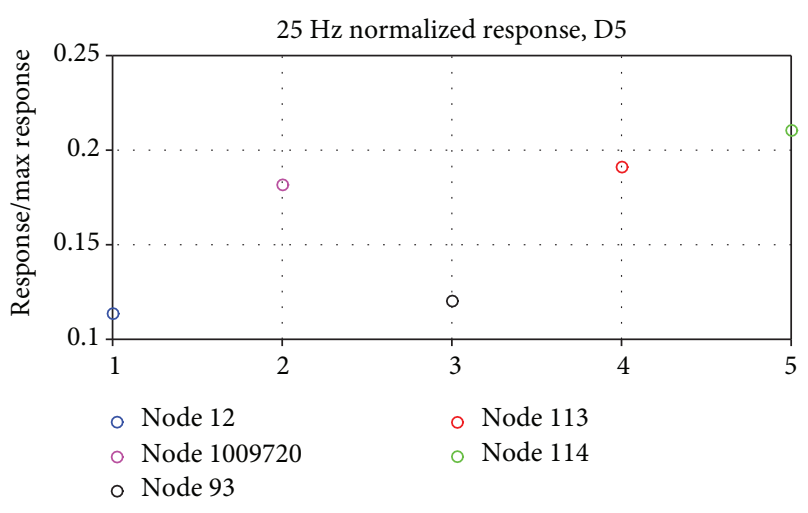

FIGURE 24: D5, $25 \mathrm{~Hz}$ normalized responses, double excitation tests.

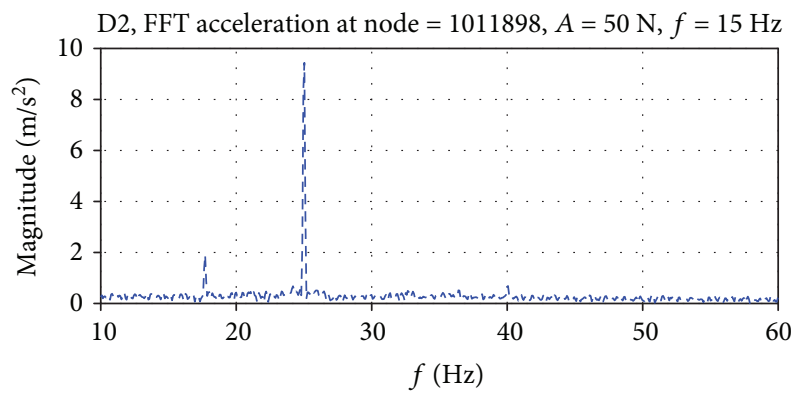

Figure 25: D2, direct response FFT, $15 \mathrm{~Hz}$ excitation test.

area, represented as a triangular excitation of duration $0.01 \mathrm{~s}$ and amplitude $20 \mathrm{~N}$. A damping factor of $1 \%$ has been set for a frequency about $7 \mathrm{~Hz}$, which is close to the first eigenfrequency of the undamaged plate. Each simulation with SOL 129 has lasted $5 \mathrm{~s}$, with a time step suitable as to follow the very rapid load story (an initial step of $0.001 \mathrm{~s}$ has been used). Accelerations in time have been computed in each excitation node and in a node located in the damaged area. Then, they have been processed by using the continuous wavelet transform (CWT) based on the Morlet wavelets [20-22]. This tool guarantees the decomposition of a time signal in components well localized in time and frequency called "wavelets." Therefore, the CWT allows looking for changes in the behavior of a signal during its evolution. Before its application, the analytic signal [11] has been obtained and then the curves exhibiting the maximum frequency content for different times have been presented in output. The purpose of the analyses has been the search for possible variations of the frequency of vibration in time, due to the nonlinear behavior of each damage. Figures 26 and 27 show the output curves for the D3 case: they exhibit slow fluctuations around the second eigenfrequency of the undamaged plate, about $11 \mathrm{~Hz}$. These little waves can be related to the variation of the local stiffness due to the contact mechanism, but models considering the

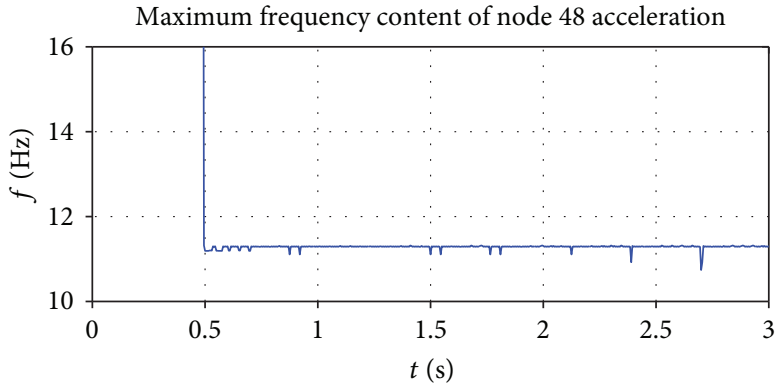

Figure 26: D3, decay test CWT, acceleration in the excitation node.

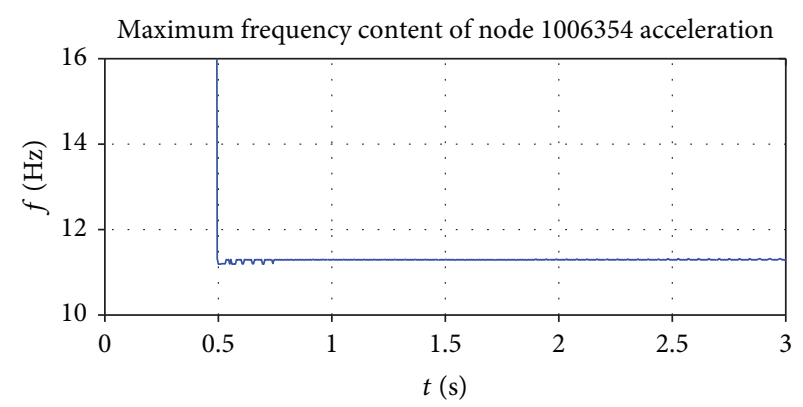

Figure 27: D3, decay test CWT, acceleration in the damaged area.

entire contact are required in order to focus this phenomenon in a better way.

3.2. FEM Analyses on Reduced Models. The analyses described before have the limitation of long times required, and this does not give the opportunity to model the entire damaged areas with the gaps. For this reason, further analyses have been executed by using reduced-order models, following the Craig-Bampton approach [23] in conjunction with the concentrated nonlinearities [24]. In particular, the boundary set of each model includes those dof connecting the bilinear springs simulating the contact mechanism (all the dof in each contact area), the excitation dof, and the measurement dof. By using MSC Nastran SOL 103, the Craig-Bampton mass and stiffness matrixes have been obtained in output (it has been chosen to consider a number of fixed interface modes equal to 14 , in order to cover a wide range of frequencies). From the results with the complete models, it has been decided to focus on the following nonlinear phenomena: superharmonics and variations of vibration frequencies in time. Thus, the following tests have been done with the software MATLAB using the matrixes obtained:

(i) Sine excitation tests: a vertical sinusoidal excitation (amplitude $=50 \mathrm{~N})$ at different frequencies $(5,10$, $15,20,25$, and $30 \mathrm{~Hz}$ ) has been placed in a node located next to each damaged area. The direct acceleration responses, obtained by using the forward finite difference method on the velocities, have been windowed with the Hanning window and then elaborated through the FFT. The first simulations done on undamped models have shown unclear 
TABLE 3: D2, superharmonic contributions, sine excitation tests.

\begin{tabular}{lccc}
\hline & $\begin{array}{c}\text { 1st } \\
\text { superharmonic }\end{array}$ & $\begin{array}{c}\text { 2nd } \\
\text { superharmonic }\end{array}$ & $\begin{array}{c}\text { 3rd } \\
\text { superharmonic }\end{array}$ \\
\hline $5 \mathrm{~Hz}$ & Yes & No & Yes \\
$10 \mathrm{~Hz}$ & Yes & No & Yes \\
$15 \mathrm{~Hz}$ & Yes & Yes & Yes \\
$20 \mathrm{~Hz}$ & Yes & Yes & Yes \\
$25 \mathrm{~Hz}$ & Yes & Yes & No \\
\hline
\end{tabular}

TABLE 4: D5, superharmonic contributions, sine excitation tests.

\begin{tabular}{cccc}
\hline & 1st & 2nd & 3rd \\
& superharmonic & superharmonic & superharmonic \\
\hline $20 \mathrm{~Hz}$ & Yes & No & Yes \\
$25 \mathrm{~Hz}$ & Yes & No & No \\
\hline
\end{tabular}

responses in those cases exhibiting nonlinear behaviors: indeed, the absence of damping causes a limited dissipation of those contributions at frequencies higher than the half of the sampling frequency (time step has been taken equal to $0.005 \mathrm{~s}$ ). For this reason, tests have been repeated on damped models: a damping matrix proportional to the stiffness matrix has been used, with the proportional constant taken as to give a damping of $1 \%$ for a frequency of $7 \mathrm{~Hz}$. The function used to solve the system of nonlinear ordinary differential equation is "ode15s," a stiff solver. In this case, tests have been done for the damaged scenarios D2 and D5, as D3 has not exhibited superharmonics in the previous simulations. Tables 3 and 4 summarize the results obtained in terms of superharmonic contributions found for the two scenarios.

Figures 28 and 29 report the FFT of the $5 \mathrm{~s}$ acceleration stories for the damaged scenario D2 with $20 \mathrm{~Hz}$ and $25 \mathrm{~Hz}$ excitations; the same results for D5 are shown in Figures 30 and 31. These figures highlight the evidence of the superharmonic presence for the $20 \mathrm{~Hz}$ and $25 \mathrm{~Hz}$ cases.

A theoretical interpretation of this aspect comes from several works in which it is stated that, in the case of crack breathing into beam structures, the higher first superharmonic behavior is excited when the excitation frequency matches one-half of the eigenfrequency $[17,25]$. Therefore, the possibility for superharmonics increases when the excitation frequency has multiples close to the eigenfrequencies of the structure. As the panel analyzed exhibits two linear modes in the range between $40 \mathrm{~Hz}$ and $50 \mathrm{~Hz}$ (see Table 2), the excitations $20 \mathrm{~Hz}$ and $25 \mathrm{~Hz}$ satisfy this condition.

(ii) Sine excitation tests with multiple acceleration measurements: once the previous tests have revealed the presence of superharmonics, the $20 \mathrm{~Hz}$ excitation

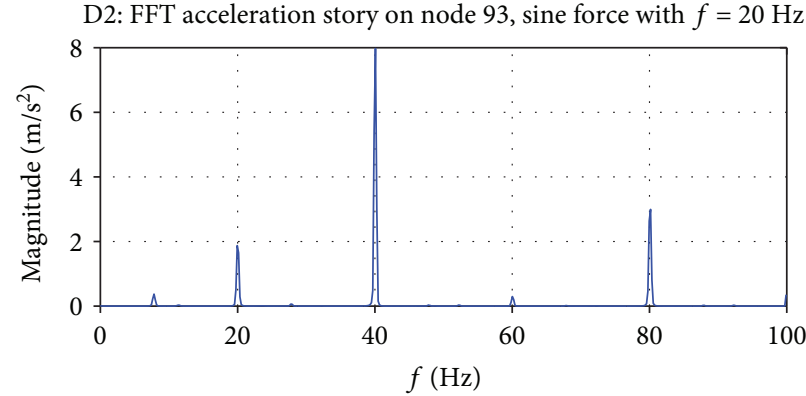

Figure 28: D2, direct response FFT, $20 \mathrm{~Hz}$ sine excitation.

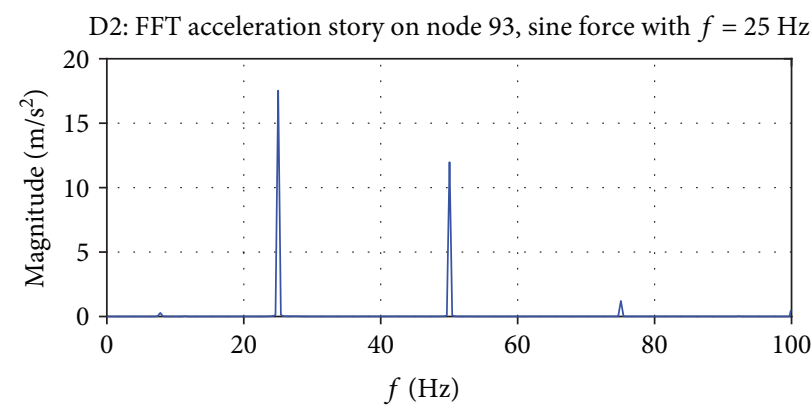

Figure 29: D2, direct response FFT, $25 \mathrm{~Hz}$ sine excitation.

D5: FFT acceleration story on node 1011502 , sine force with $f=20 \mathrm{~Hz}$

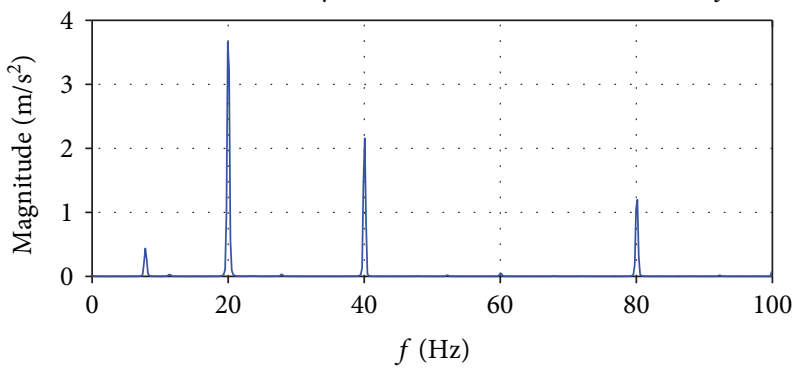

FIGURE 30: D5, direct response FFT, $20 \mathrm{~Hz}$ sine excitation.

simulations have been repeated by computing the accelerations in 10 nodes along the damaged stiffeners, at a distance one to each other of about $106.6 \mathrm{~mm}$ (see Figure 32 for the node location). This procedure has aimed at finding possible correlations between the superharmonic contributions and each damaged area (for both D2 and D5, the damage is located at one end of the stiffener). In the case of D2 scenario, the first and third superharmonic contributions have resulted sensitive to the localization. Figure 33 reports the normalized trend for the first superharmonic amplitudes. For D5, the same output is shown in Figure 34, exhibiting the localization trend. Damages D2 and D5 are located close to node 93 (see Figures 17 and 18).

(iii) Sine excitation tests repeated with a different force position. The multiple acceleration measurement tests have been executed exciting in node 12, which 
D5: FFT acceleration story on node 1011502, sine force with $f=25 \mathrm{~Hz}$

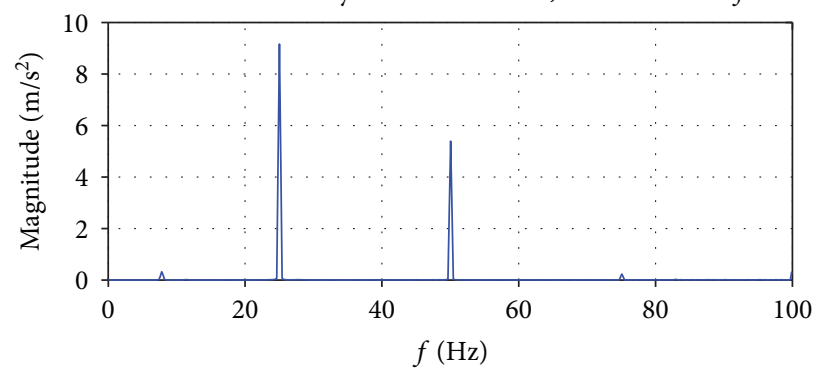

FIgURE 31: D5, direct response FFT, $25 \mathrm{~Hz}$ sine excitation.

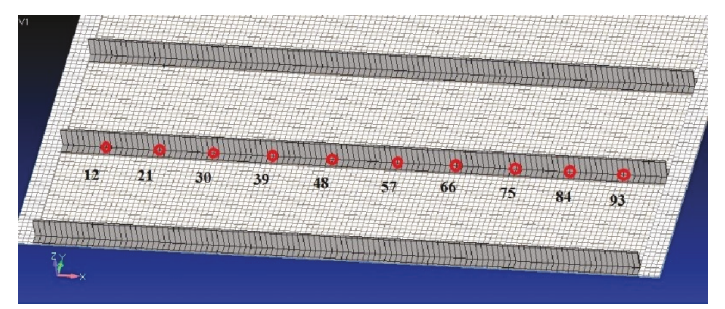

Figure 32: Positions of the measuring nodes for experimental superharmonic tests.

D2, $20 \mathrm{~Hz}$ sine excitation force on node 93, first superharmonic

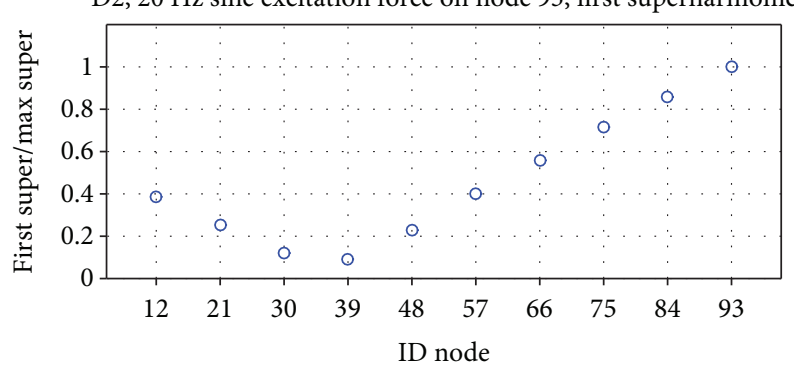

FIGURE 33: D2, $20 \mathrm{~Hz}$ excitation, normalized 1st superharmonic.

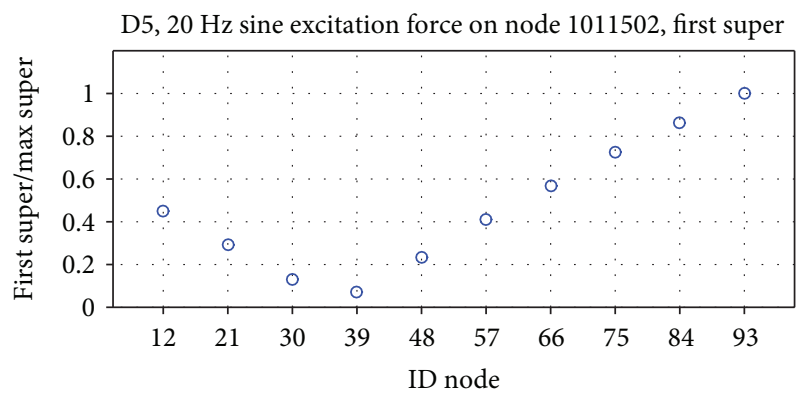

Figure 34: D5, $20 \mathrm{~Hz}$ excitation, normalized 1st superharmonic.

is located on the opposite side of the damages D2 and D5 (see Figures 17 and 18). In this case, the relevant trend is that obtained for the first superharmonic contributions of the D2 scenario (Figure 35). Even if the localization trend has been obtained also for D5, the absolute values are not significant in this case (the $40 \mathrm{~Hz}$ peak in node 93 equals $0.0361 \mathrm{~m} / \mathrm{s}^{2}$, while the $20 \mathrm{~Hz}$ one is $3.995 \mathrm{~m} / \mathrm{s}^{2}$ ). (iv) Decay tests: as done for the tests with complete models, an impulsive vertical load has been applied next to each damaged area, with the same characteristics of the one used before. A damping matrix proportional to the stiffness one has been introduced in the model. $4 \mathrm{~s}$ acceleration signals with a resolution of $0.005 \mathrm{~s}$ have been recorded in the excitation node and in a node close to each damaged area. Each signal has been transformed into its analytic version and processed by using the CWT with Morlet wavelets. Results have highlighted relevant fluctuations of the main vibration frequency around an eigenfrequency after a transition time, for the accelerations in the damaged area nodes (Figures 36-38).

(v) As observed for the D3 results with the complete models, the fluctuations in this case are around the second eigenfrequency $(11 \mathrm{~Hz})$. On the other hand, they are around the first eigenfrequency $(8 \mathrm{~Hz})$ for D2 and D5 cases. This fact is due to the relation between the position of the excitation node and the mode shapes: the first mode, with a frequency about $8 \mathrm{~Hz}$, is a torsion (see Figure 8 ); the second mode, with a frequency about $11 \mathrm{~Hz}$, is a flexion around the longitudinal direction (see Figure 9) and thus forces the central part of the structure to vibrate vertically. Thus, the central excitation used for D3 excites the second mode more than the first one.

3.3. Comments on Numerical Results. The numerical tests described have been executed with the aim of finding suitable nonlinear phenomena for an experimental damage detection technique. From the results discussed, it has been decided to focus on two phenomena highlighted by the use of the reduced-order simulations: the presence of superharmonics with sine excitation tests and the fluctuations of the main vibration frequency for decay tests. Both these aspects are theoretically justified by the analyses described in Section 2 . Indeed, the superharmonic presence is a consequence of the nonlinear response described by the Volterra series, while the variation of frequency of vibration results from the activation of a local bilinear stiffness behavior. Double sine excitation tests executed with the complete models have not been considered in the experimental activity as single excitations are more practical to be managed than double excitations, with the consequent impact on time required for the analyses and ease of testing.

In order to exhibit a comparison between the numerical results obtained in the cases of complete and reduced models, Figures 39 and 40 report the first superharmonic contributions found for the $20 \mathrm{~Hz}$ excitation on node 93 along the acceleration measuring nodes used for sine excitation tests with multiple acceleration measurements. The damaged case considered is D2. These contributions have been obtained for both the simulations, with correlated orders of magnitudes. Moreover, Figures 41 and 42 show the comparison between the FFT of the direct response (that obtained on node 93). 


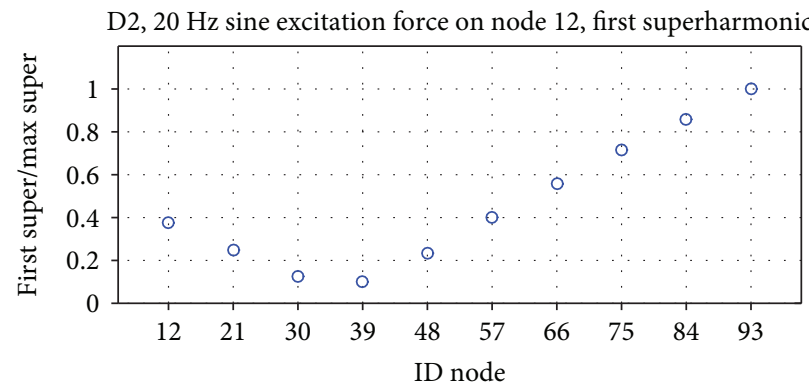

FIgURE 35: D2, $20 \mathrm{~Hz}$ excitation in node 12, normalized 1st superharmonic.

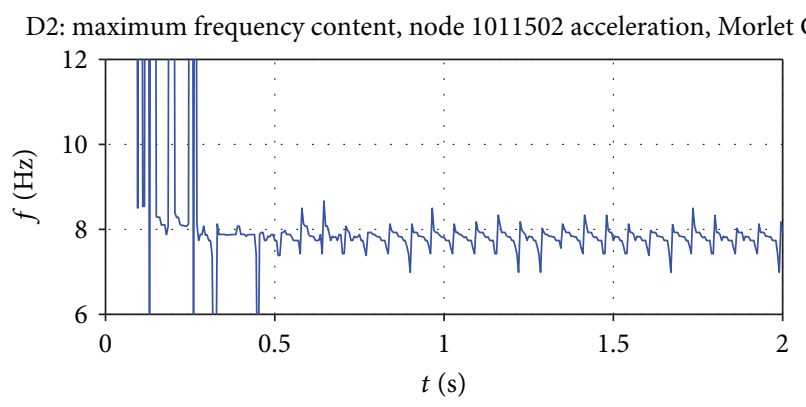

Figure 36: D2, decay test CWT, acceleration in the damaged node.

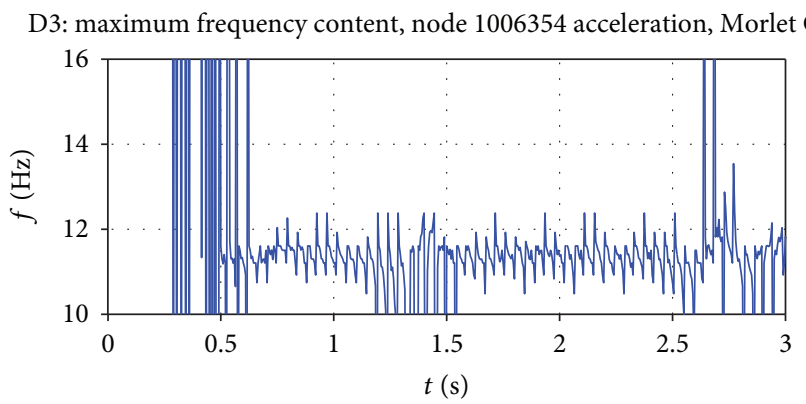

Figure 37: D3, decay test CWT, acceleration in the damaged node.

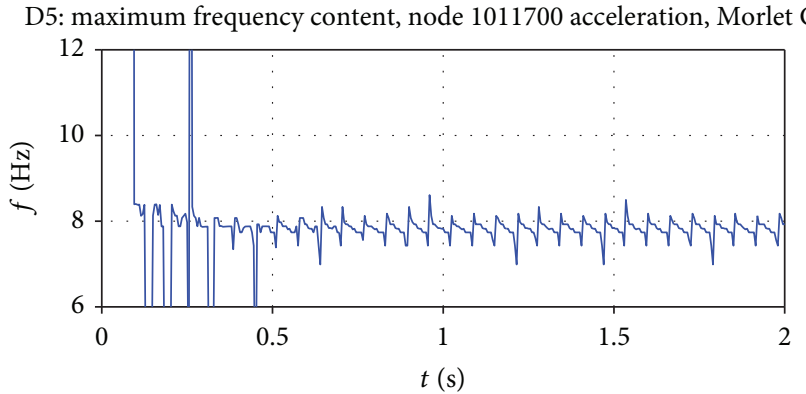

FIGURE 38: D5, decay test CWT, acceleration in the damaged node.

The comparisons shown must be completed highlighting that full models consider a limited area for the gap mechanism implementation in each damaged place. Moreover, reduced model simulations have been executed introducing a damping has written in Section 3.2. These relevant aspects, together

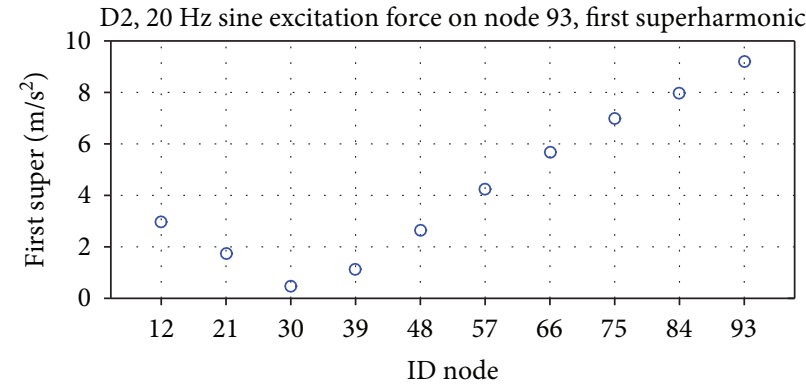

FIgURe 39: D2, $20 \mathrm{~Hz}$ excitation 1st superharmonic, full model.

with the simplification introduced by the Craig-Bampton approach, justify the difference in the FFT contributions, the detection of relevant contributions at higher superharmonics only in the case of reduced models, and the evident difference in the fluctuations resulting from decay tests. 


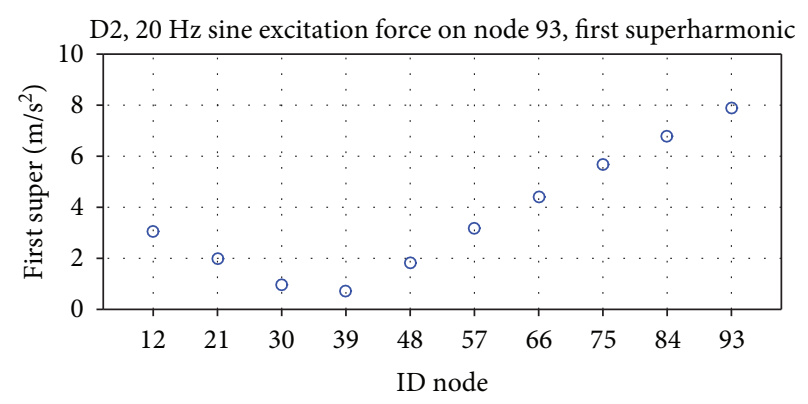

Figure 40: D2, $20 \mathrm{~Hz}$ excitation 1st superharmonic, reduced model.

D2, FFT acceleration story on node $93, f=20 \mathrm{~Hz}$, sine force on node 93

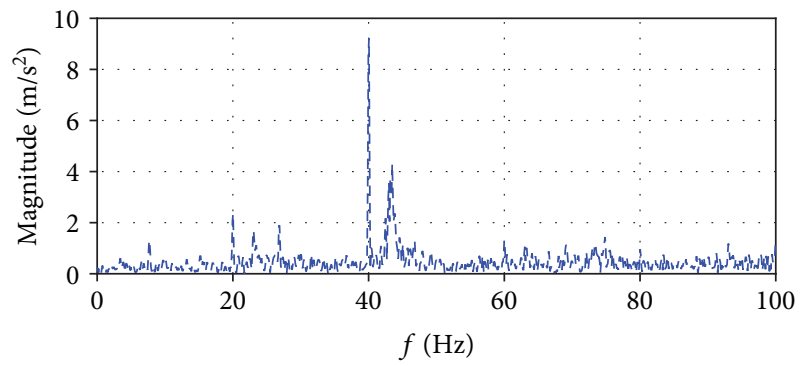

FIgURE 41: D2, node 93 acceleration, FFT, full model.

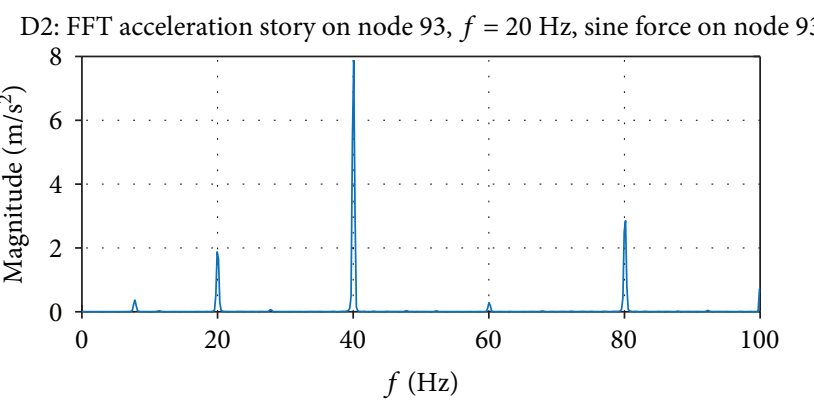

FIgURE 42: D2, node 93 acceleration, FFT, reduced model.

It is important to underline that the numerical simulations have been based on model assumptions. In particular, the intuitive idea of the local bilinear stiffness behavior of each contact has been followed without an energetic formalization of the contact mechanism. Moreover, the contact has been modeled only in each damaged area, so where it has been supposed that the nonlinear phenomena show their main effects. Finally, each link between the stiffeners and the baseplate has been realized merging the common nodes.

The detail of time integration parameters and model setup for the numerical analyses is present in [18].

\section{Experimental Tests}

The experimental tests have been conducted with the panel suspended by the use of an elastic cable, which supports the structure at the two extremities. Figure 43 shows the detail of the hanging system. The interference of the low frequency of oscillation due to the cord is limited as to consider the structure in the free-free condition. Both the sine excitation

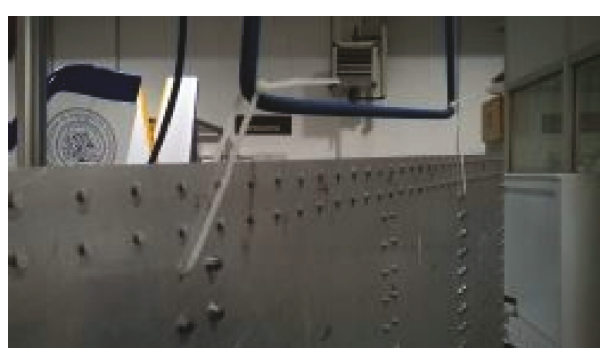

FIGURE 43: Detail of the hanging system.

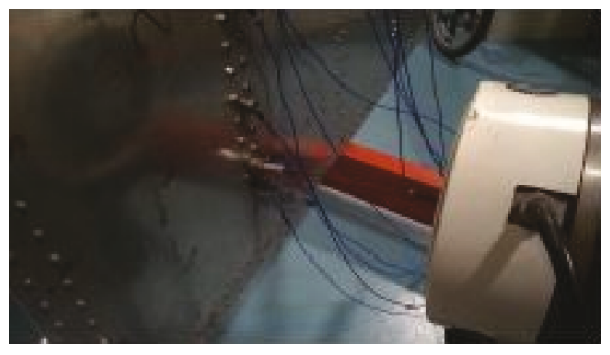

FIgURE 44: Detail of the rod for panel-shaker connection.

TABLE 5: Load levels used for the sine excitation tests.

\begin{tabular}{lcc}
\hline Load level & Voltage range $(\mathrm{V})$ & Load range $(\mathrm{N})$ \\
\hline 1 & 0.05 & 12.4 \\
2 & 0.1 & 23.6 \\
3 & 0.15 & 34.1 \\
4 & 0.2 & 44.3 \\
5 & 0.25 & 54 \\
6 & 0.3 & 62.7 \\
\hline
\end{tabular}

tests and the decay tests have dealt with the measure of accelerations by using the "PCB Piezotronics" accelerometers. The data acquisition and postprocessing are carried out using the Test-Lab software by Siemens.

All the accelerometers are located on the side of the baseplate without the stiffeners.

4.1. Sine Excitation Tests for Superharmonics. Tests for superharmonics have been conducted by forcing the reference structure and the damaged scenarios in two different positions. The first one corresponds to that of node 12 and the second one is the place of node 93. They are located on the opposite sides of the damaged stiffeners, as shown in Figures 17-19. For each single excitation, six load levels have been imposed. Figure 44 shows the detail of the stinger for the panel-shaker connection, and Table 5 reports the six load levels (the voltage range imposed to the signal generator and the corresponding load level measured by the load cell).

For each excitation, ten accelerations have been recorded along the second stiffener in those points corresponding to the measuring nodes of the numerical simulations. Figure 32 shows the location of the measuring and excitation nodes along the second stiffener. Each single test has lasted $10 \mathrm{~s}$. Each signal has been filtered with an imposed band of $1024 \mathrm{~Hz}$ and then amplified before its digitalization. 
TABLE 6: Number of superharmonic peaks $(N)$ and maximum superharmonic frequency content $(f)$.

\begin{tabular}{lcccc}
\hline Case & $\begin{array}{c}N, \\
\text { node } 12\end{array}$ & $\begin{array}{c}f, \text { node } \\
12(\mathrm{~Hz})\end{array}$ & $\begin{array}{c}N, \\
\text { node } 93\end{array}$ & $\begin{array}{c}f, \text { node } \\
93(\mathrm{~Hz})\end{array}$ \\
\hline Reference & 7 & 160 & 2 & 60 \\
D2 & 2 & 80 & 24 & 980 \\
D3 & 2 & 60 & 26 & 820 \\
D5 & 19 & 700 & 9 & 820 \\
\hline
\end{tabular}

The final numerical data have been processed by using the software MATLAB (windowing with the Hanning window and FFT). For each condition (reference structure, D2, D3, and D5), the following 24 tests have been executed:

(i) $20 \mathrm{~Hz}$ sinusoidal excitation in node 12, with the six load levels

(ii) $20 \mathrm{~Hz}$ sinusoidal excitation in node 93, with the six load levels

(iii) $25 \mathrm{~Hz}$ sinusoidal excitation in node 12, with the six load levels

(iv) $25 \mathrm{~Hz}$ sinusoidal excitation in node 93, with the six load levels

The choice for the excitation frequencies result from the numerical analyses.

By analyzing the direct responses, the presence of superharmonics has been found also for the reference condition. Moreover, several superharmonics have been detected for each damaged scenario analyzed [18]. This aspect is probably due to the discrete nature of each connection and marks a fundamental consequence: the detection alone by finding the nonlinear phenomena is not possible. Table 6 indicates, for each direct response with the $20 \mathrm{~Hz}$ excitation, the number of superharmonic peaks $(N)$ identified and the corresponding frequency range $(f)$ : the counted peaks are those ones having a contribution higher than the $10 \%$ of the highest response in each spectrum.

The analyses of the direct responses for the $25 \mathrm{~Hz}$ excitation have revealed the presence of superharmonics with more limited contributions. For this reason, it has been decided to focus on the $20 \mathrm{~Hz}$ excitation cases. As done for the numerical tests, the first superharmonic contributions $(40 \mathrm{~Hz})$ in all the measuring nodes have been compared. In particular, for all the cases, these contributions and their normalized values (obtained dividing the data by the highest value in each test) have been reported into figures representing the first superharmonics along the measuring nodes for all the load levels.

4.1.1. Reference Structure. Figures 45 and 46 report the behavior of the first superharmonics along the measuring nodes for all the load levels, exciting in node 12 and node 93. The trends are mainly symmetrical, and the nonlinear phenomena is approximately proportional changing the load levels, as visible from the normalized trends.
4.1.2. D2 Scenario. Figures 47 and 48 report the same figures for the D2 scenario. In the case of excitation in node 93, the force is located in that side of the stiffener closer to the damaged area. As a consequence, the contributions grow towards that direction, with the exception of lower load levels $(0.05 \mathrm{~V}$ and $0.1 \mathrm{~V})$. In the case of excitation in node 12 , even if the maximum contributions are those in the excitation point, the increasing of the load level determines a nonlinear augmentation of the contribution in the damaged area, as visible from the normalized trend. The trigger is reached with load level $0.2 \mathrm{~V}$.

4.1.3. D3 Scenario. Figures 49 and 50 report the same figures for the D3 case. As for the reference structure, the trends are mainly symmetrical.

4.1.4. D5 Scenario. Figures 51 and 52 report the same figures for the D5 scenario. In this case, both the trends own the contributions growing towards node 93, the point closer to the damaged area.

4.1.5. Comments on Results. The analyses of the first superharmonics have revealed the possibility to localize the end damages (D2 and D5) in a qualitative way by comparing the responses to the different load levels and exciting at the opposite sides. Only for those cases of end damages, growing trend oriented towards a predominant direction has been observed. Moreover, for the case of excitation in node 12 in the D2 scenario, the nonhomogeneity explained by the Volterra series has resulted in the increasing of the amount of the contributions of those nodes located in the damaged area with the augmentation of the load level. Therefore, the load level acts like a trigger able to activate the nonlinear contact mechanism. Figure 53 reports the ratios between the first superharmonic magnitudes in load level $0.3 \mathrm{~V}$ and load level $0.05 \mathrm{~V}$ for all the measuring points for this case: the highest value is that of the damaged area.

Similar conclusions for the qualitative localization are possible analyzing other superharmonics. In particular, [18] reports the results obtained with the second $(60 \mathrm{~Hz})$ and the third $(80 \mathrm{~Hz})$ ones.

4.2. Decay Tests. Decay tests have been executed by using the PCB instrumented hammer shown in Figure 54.

For each damaged scenario, two impulsive excitations have been applied: the first one located next to the damaged region and the second one located at one end of the damaged stiffener. For each test, three accelerations have been recorded: one in point $A$, located near the damaged area; one in point $B$, located in the damaged area; and one in the point corresponding to node 12 , at one end of the stiffener. Figures 55-57 show the location of the three measuring points for each damaged scenario. Each $10 \mathrm{~s}$ signal has been firstly filtered with an imposed band of $1024 \mathrm{~Hz}$ and then amplified before its digitalization. The final numerical data have been processed by using the software MATLAB (transformation through the Hilbert transform as to obtain the analytic version of each signal and CWT). 


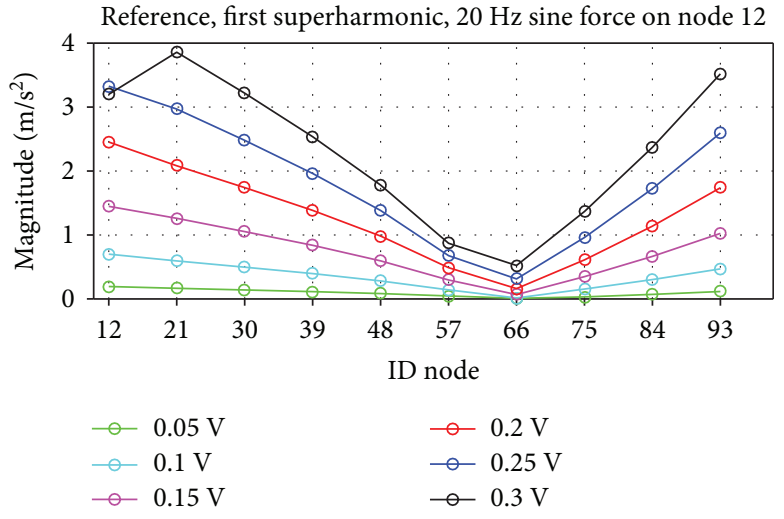

(a)

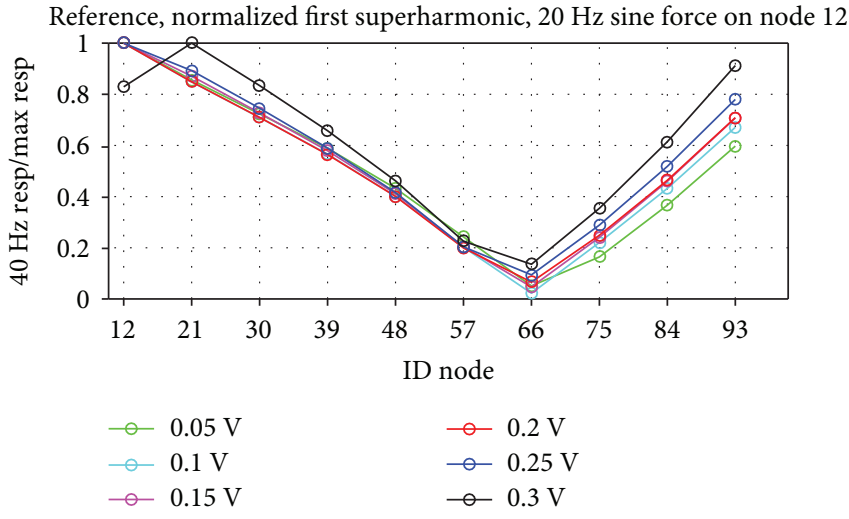

(b)

FIgURE 45: $40 \mathrm{~Hz}$ FFT magnitudes, $20 \mathrm{~Hz}$ sine excitation force applied to node 12, reference structure.

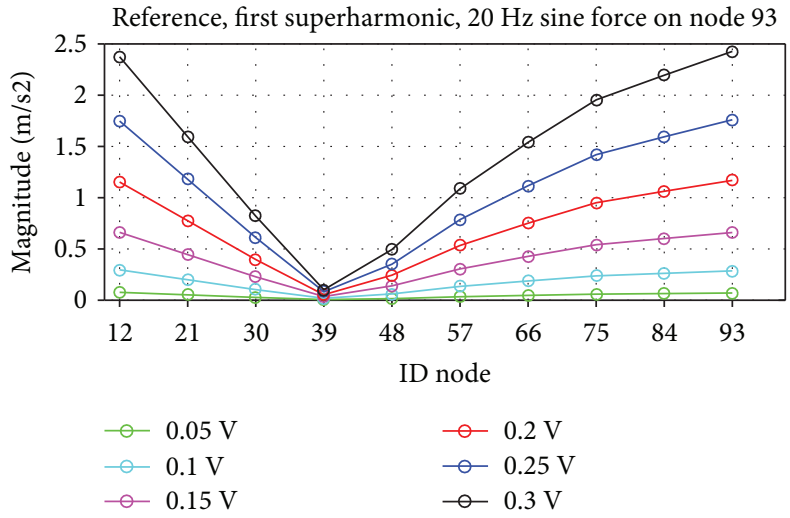

(a)

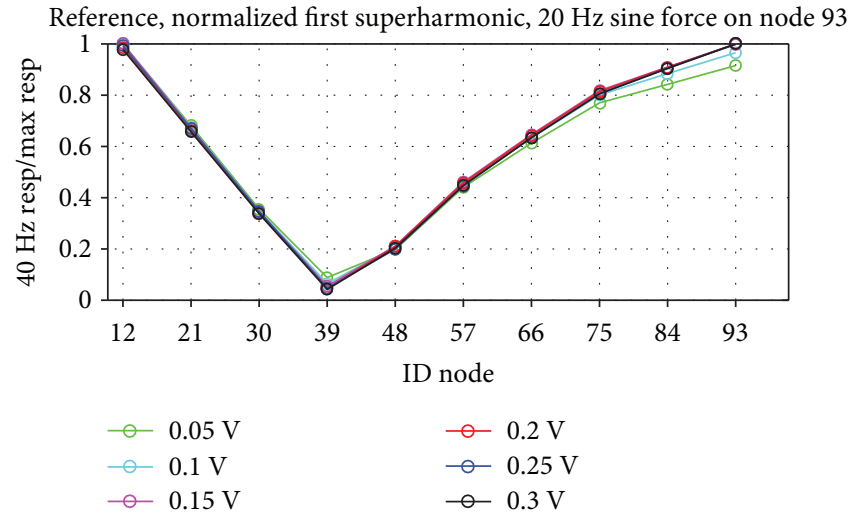

(b)

Figure 46: $40 \mathrm{~Hz}$ FFT magnitudes, $20 \mathrm{~Hz}$ sine excitation force applied to node 93, reference structure.

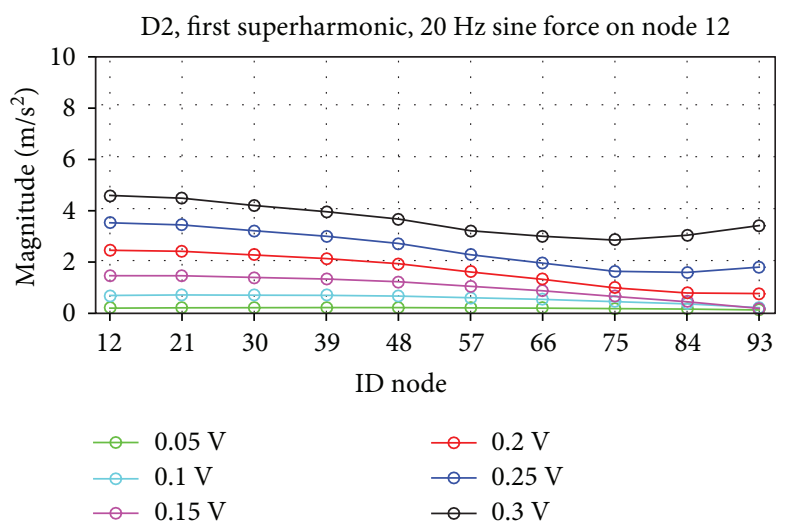

(a)

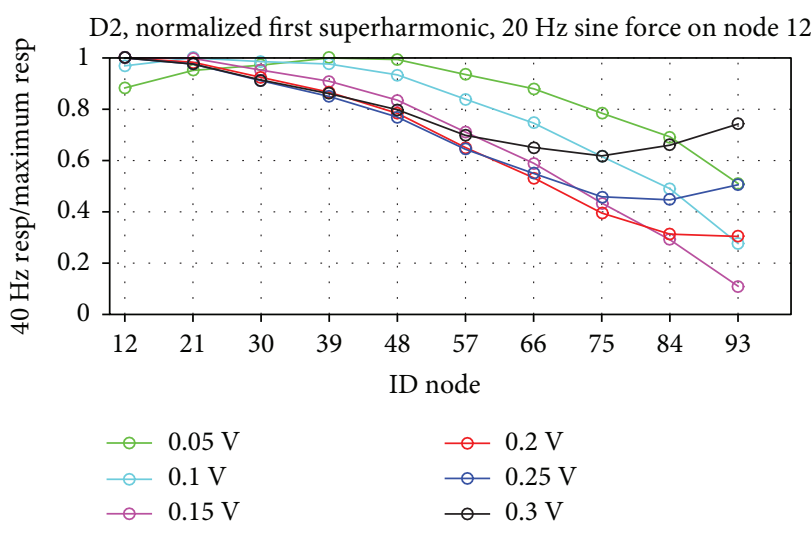

(b)

FIGURE 47: $40 \mathrm{~Hz}$ FFT magnitudes, $20 \mathrm{~Hz}$ sine excitation force applied to node 12, D2 scenario.

4.2.1. D2 Scenario. The CWT has been firstly applied considering a frequency range between $5 \mathrm{~Hz}$ and $30 \mathrm{~Hz}$. This allows the elimination of the low-frequency contribution related to the elastic cable used to suspend the structure. By the data processing, the main frequency content in time has been obtained. Two contributions have been observed in the acceleration stories: one at $8 \mathrm{~Hz}$, so close to the first eigenfrequency of the undamaged structure, and one at $24 \mathrm{~Hz}$ [18]. In order to focus on the first eigenfrequency behavior as done in the numerical tests, the analysis has been repeated with a frequency range between $5 \mathrm{~Hz}$ and $10 \mathrm{~Hz}$. Figures 58 and 59 report the comparisons of the maximum frequency content 


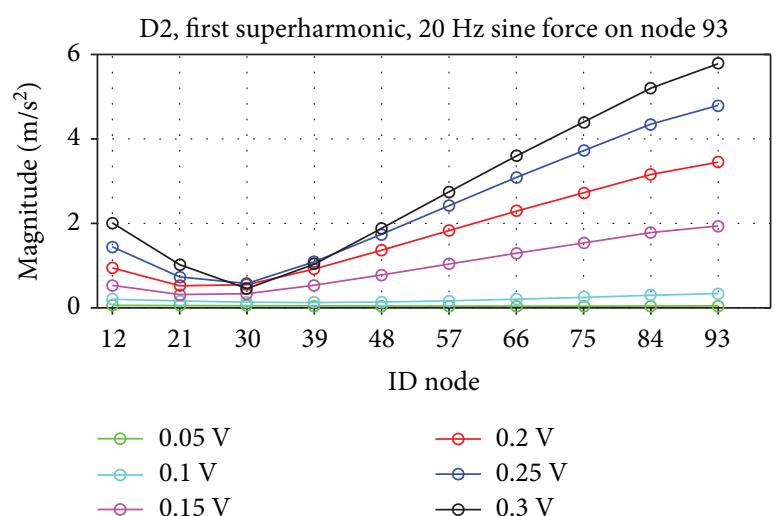

(a)

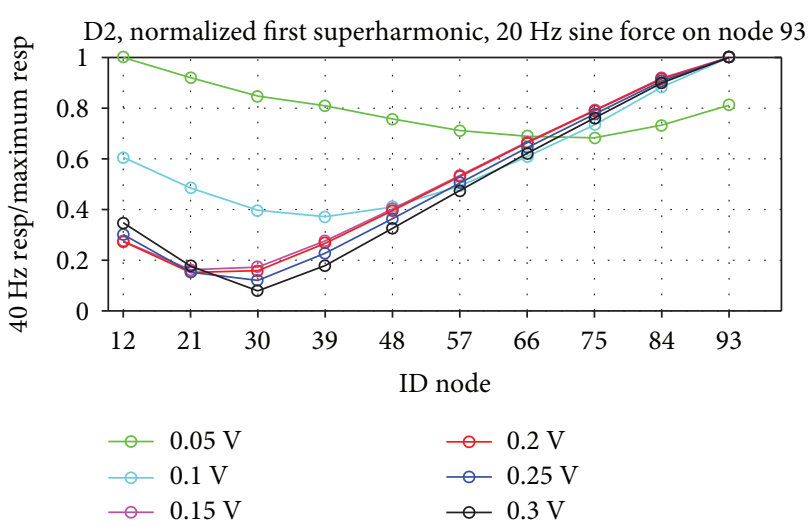

(b)

FIgURe 48: $40 \mathrm{~Hz}$ FFT magnitudes, $20 \mathrm{~Hz}$ sine excitation force applied to node 93, D2 scenario.

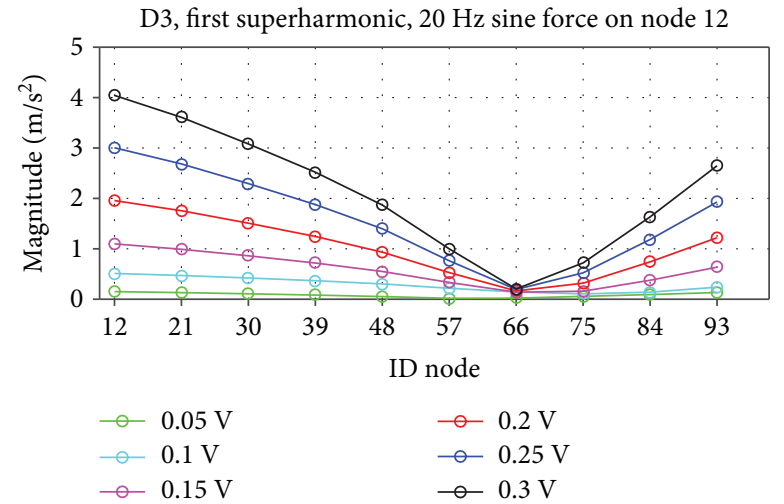

(a)

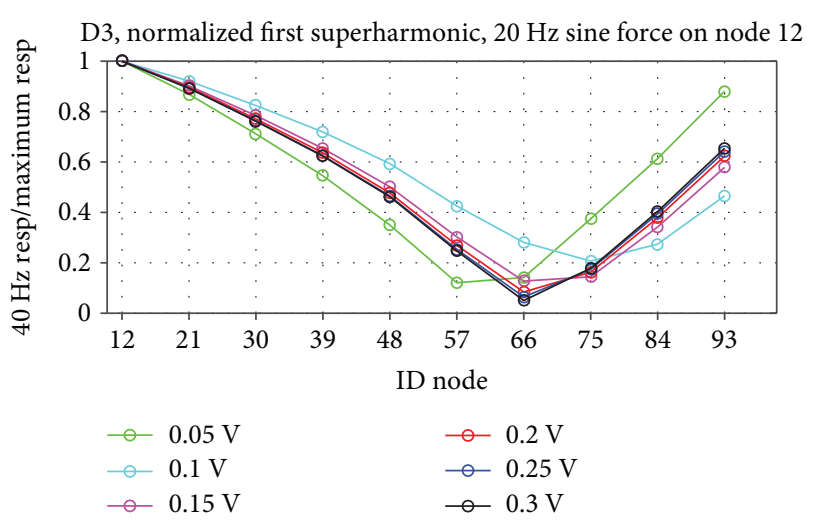

(b)

FIgURe 49: $40 \mathrm{~Hz}$ FFT magnitudes, $20 \mathrm{~Hz}$ sine excitation force applied to node 12, D3 scenario.

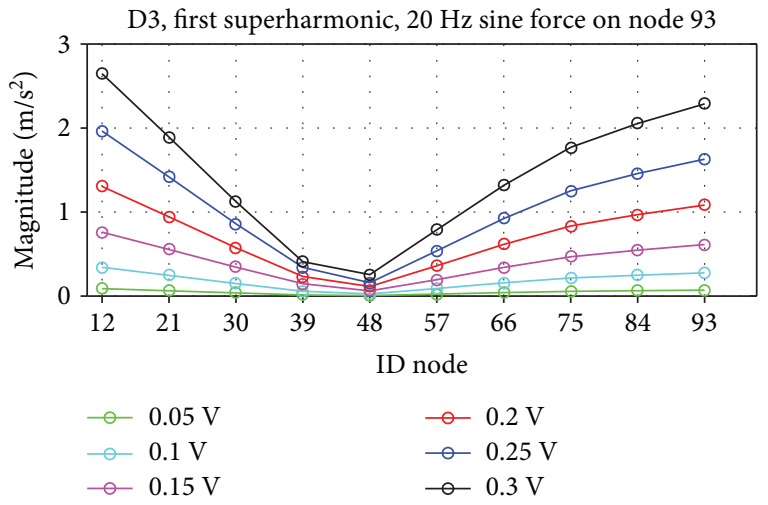

(a)

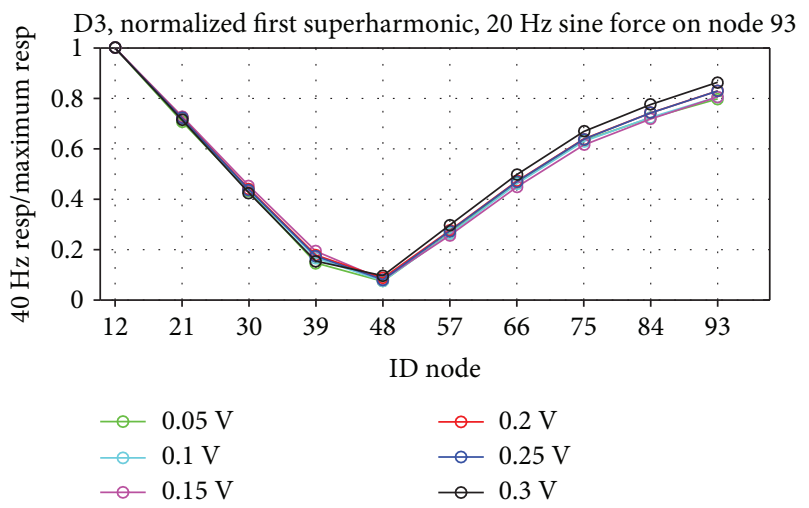

(b)

FIgURe 50: $40 \mathrm{~Hz}$ FFT magnitudes, $20 \mathrm{~Hz}$ sine excitation force applied to node 93, D3 scenario.

in this range for the two excitation tests done. The three curves included represent each acceleration measured.

Fluctuations in the contribution are evident. The oscillations for point $B$ (black curves) are higher than the other ones, for both cases. Moreover, the oscillations in point $A$ (blue curve) are higher than the ones in node 12 (red curves). As point $B$ is the one in the damaged area, an explanation for the phenomenon is that this region has the highest variation of stiffness in time. From the results, it is also possible to state that all the structure exhibits main frequency oscillations. In order to compare this situation with the undamaged one, the same tests have been repeated with the original structure. Results are reported in Figures 60 and 61. 


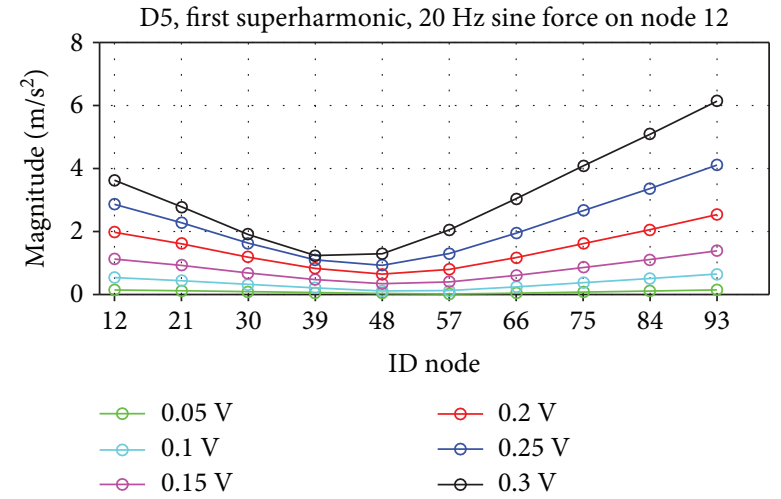

(a)

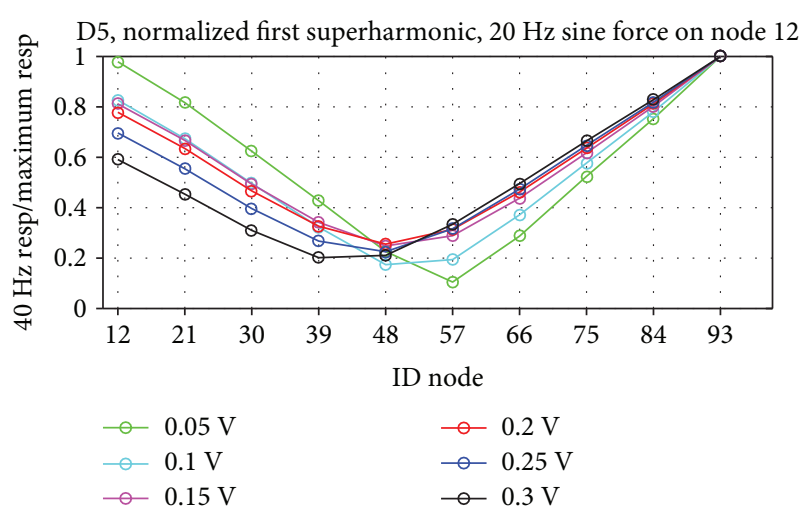

(b)

FIgURE 51: $40 \mathrm{~Hz}$ FFT magnitudes, $20 \mathrm{~Hz}$ sine excitation force applied to node 12, D5 scenario.

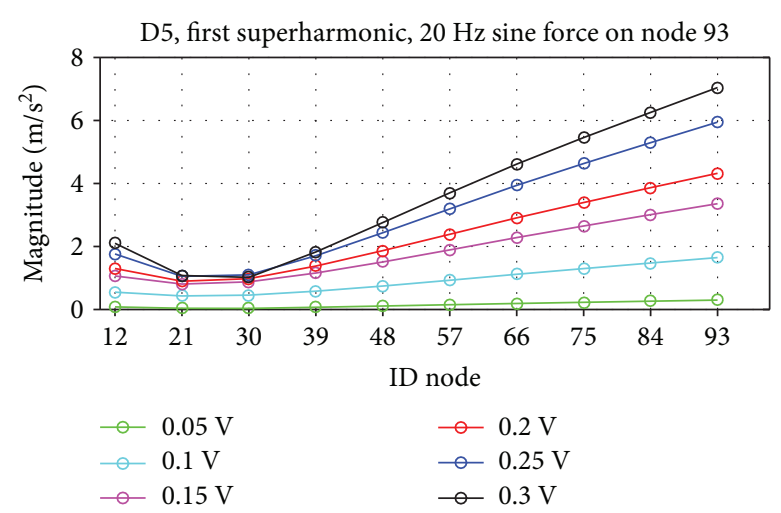

(a)

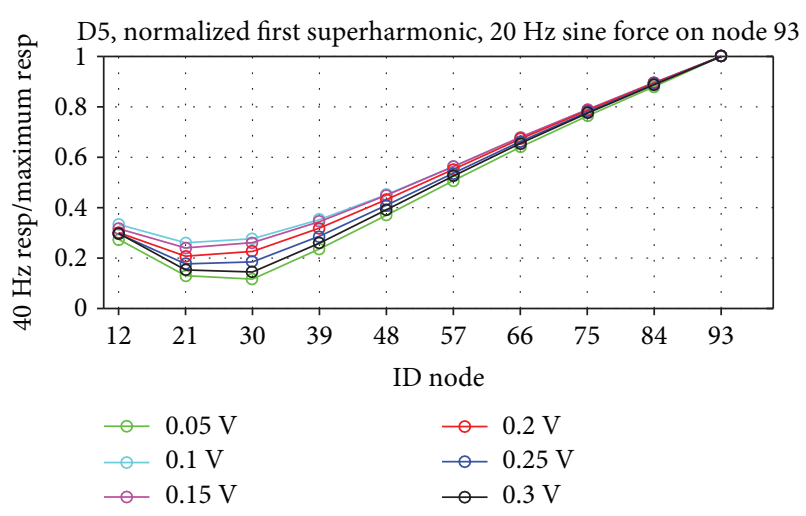

(b)

FIgURE 52: $40 \mathrm{~Hz}$ FFT magnitudes, $20 \mathrm{~Hz}$ sine excitation force applied to node 93, D5 scenario.

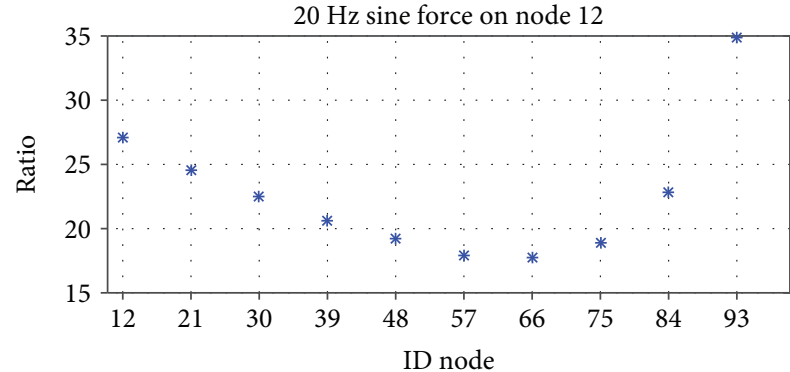

Figure 53: D2, $20 \mathrm{~Hz}$ sine excitation force in node 12, ratios between load levels.

In this case, the oscillation ranges are the same for all the points. The visible abrupt ends are due to the absence of further more acceleration time data after the final time indicated: the test recordings last $14-15 \mathrm{~s}$.

4.2.2. D3 Scenario. The elaborations done for the $\mathrm{D} 3$ case are the same as those for the $\mathrm{D} 2$ one, with the exception that the range of frequencies used for the second analyses goes from $5 \mathrm{~Hz}$ to $13 \mathrm{~Hz}$. In the test done exciting near the damage, the acceleration analysis for point $B$ has revealed a very

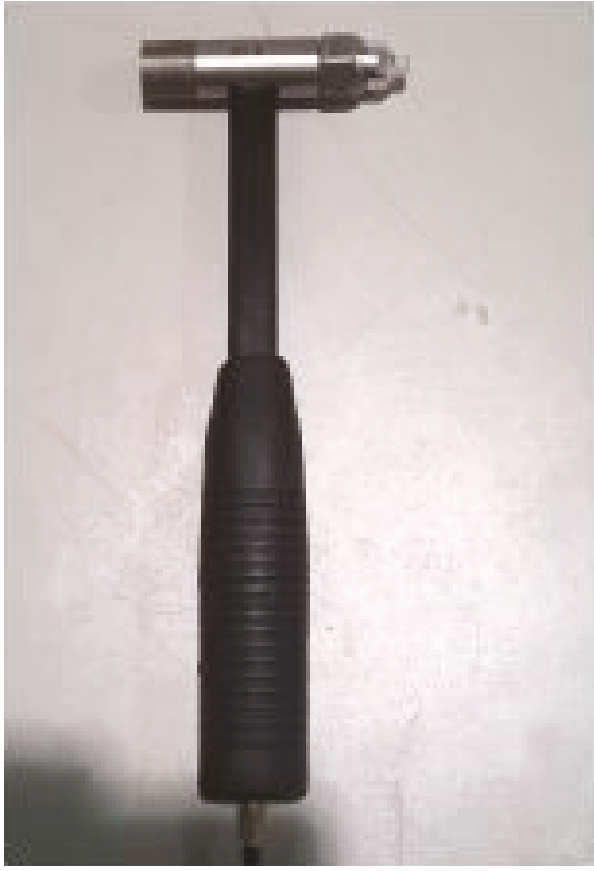

FiguRe 54: Instrumented hammer used for decay tests. 


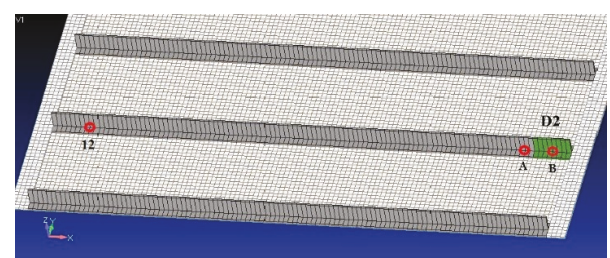

FIgURe 55: Positions of the measuring nodes for decay tests, damage D2.

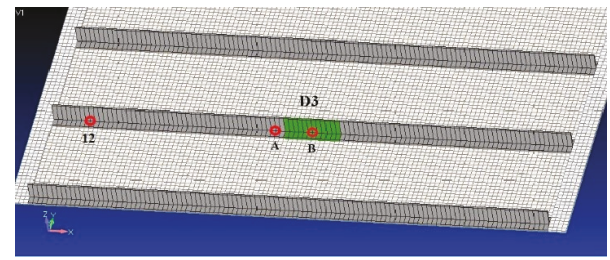

Figure 56: Positions of the measuring nodes for decay tests, damage D3.

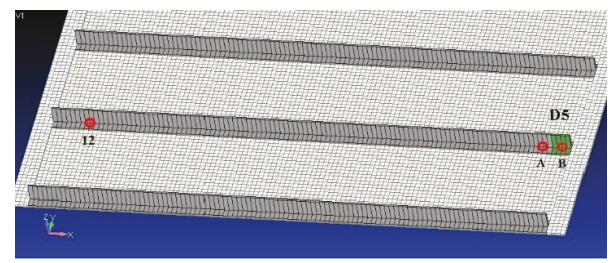

FIgure 57: Positions of the measuring nodes for decay tests, damage D5.

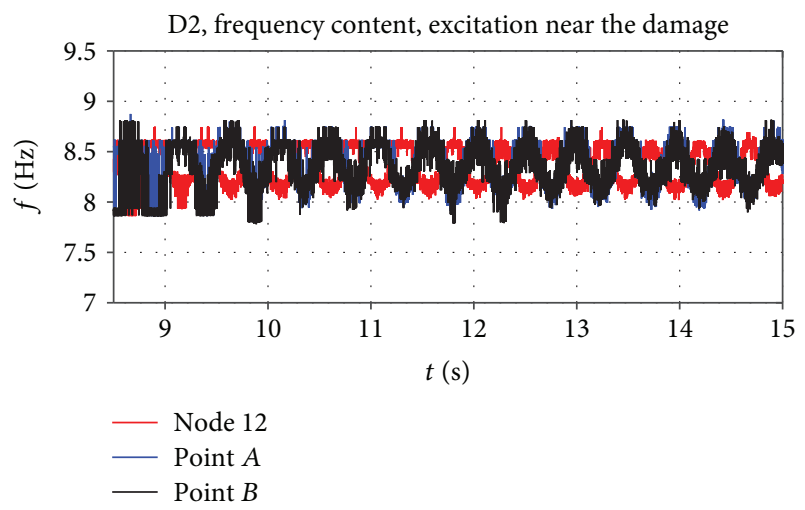

FIgURE 58: D2, maximum frequency, excitation near the damage.

strong fluctuation around the second eigenfrequency of the undamaged structure $(11 \mathrm{~Hz})$, as reported in Figure 62 . Moreover, Figure 63 shows the comparisons of the main frequency oscillations for the accelerations recorded exciting far from the damage (the abrupt ends are present according to what was stated at the end of the previous section).

As visible from Figure 63, the acceleration in node 12 owns a dominant frequency content represented by the first eigenfrequency. On the other hand, as known from the numerical analyses, point $A$ and point $B$ exhibit fluctuations around the second eigenfrequency. The amplitude of the

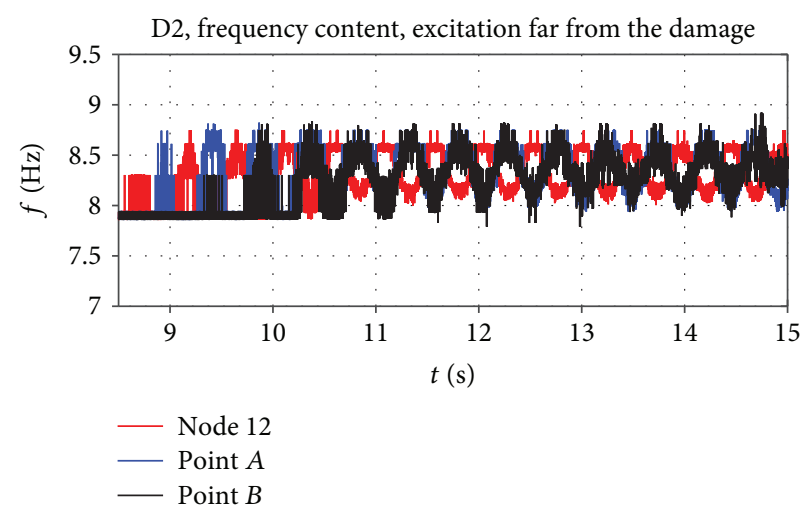

Figure 59: D2, maximum frequency, excitation far from the damage.

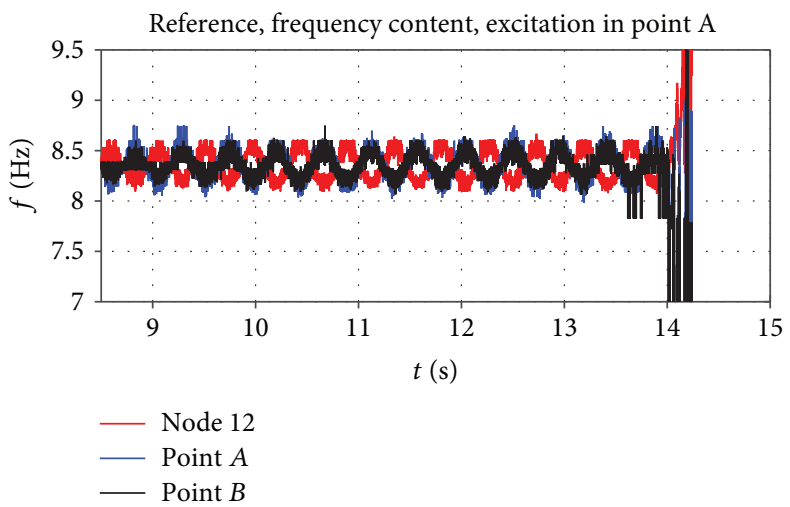

FIGURE 60: Undamaged case, excitation near the damage.

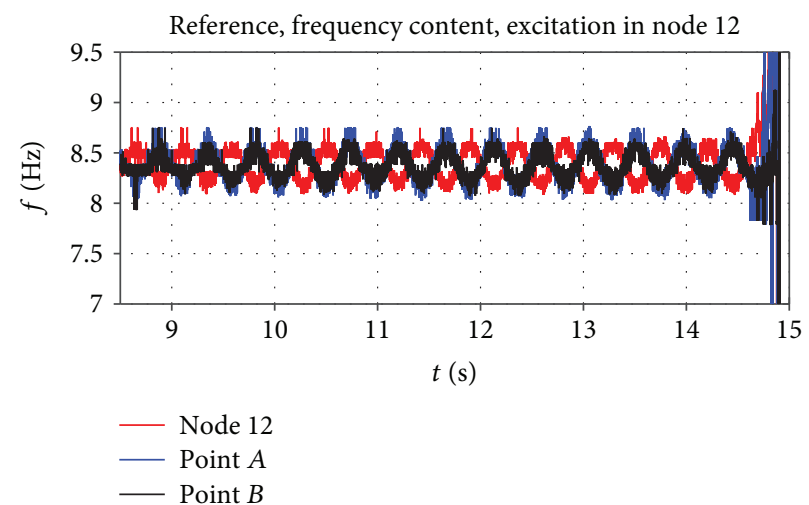

FIgURE 61: Undamaged case, excitation far from the damage.

oscillations in point $B$ located in the damaged area is higher than the one for point $A$.

4.2.3. D5 Scenario. The elaborations done for the D5 case are the same as those for the previous cases. The frequency ranges for the results reported go from $5 \mathrm{~Hz}$ to $10 \mathrm{~Hz}$. Figures 64 and 65 report the comparisons of the maximum frequency content in this range for the two excitation tests done (abrupt ends are present according to what was stated at the end of Section 4.2.1). 


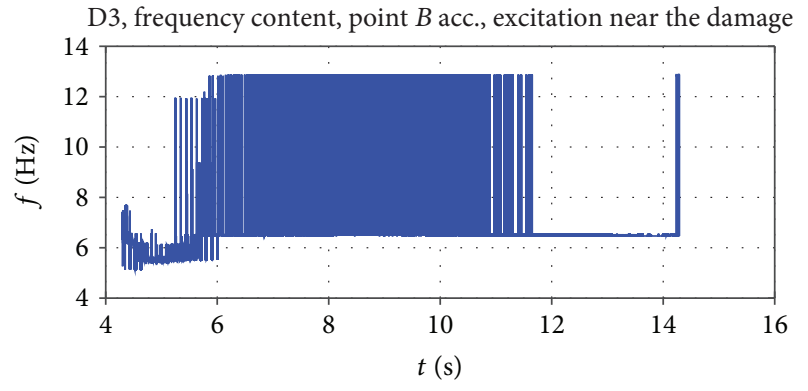

FIGURE 62: D3, maximum frequency, point $B$, excitation near the damage.

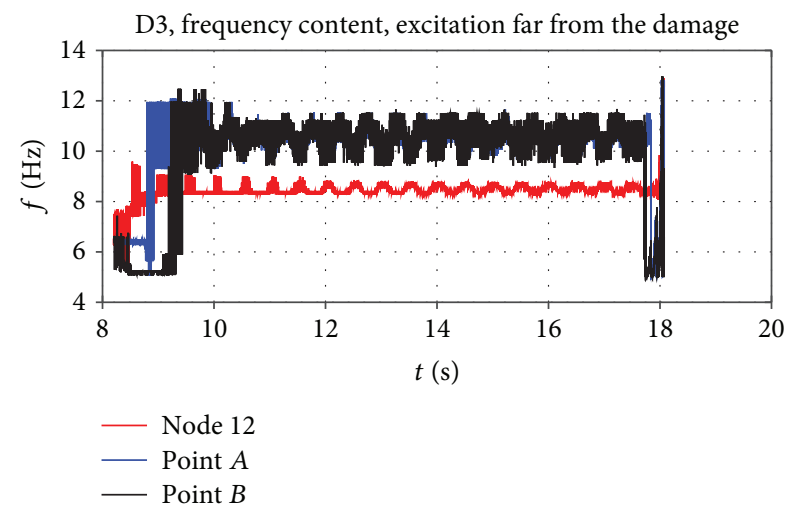

Figure 63: D3, maximum frequency, excitation far from the damage.

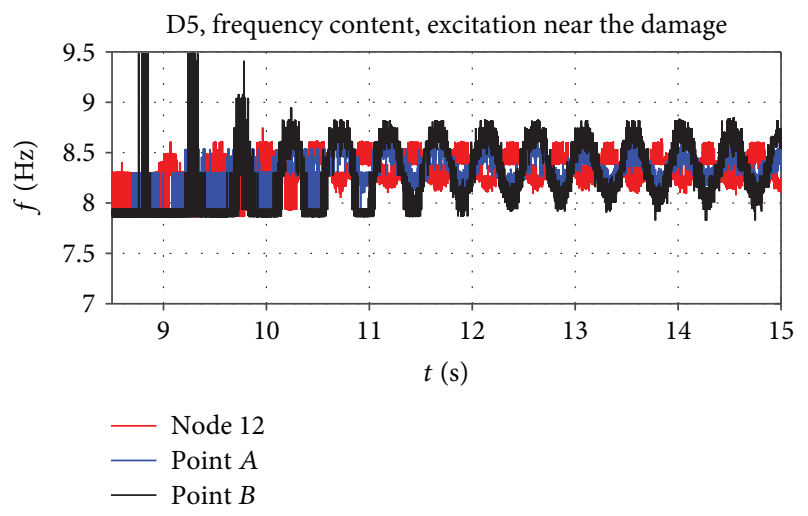

Figure 64: D5, maximum frequency, excitation near the damage.

Again, the trend of the amplitudes increasing moving from node 12 to point $A$ and point $B$ is evident.

4.2.4. Comments on Results. The analyses from decay tests have underlined some relevant points. At first, the main frequency fluctuation expected from numerical tests has been found for all the measurement points. As understood by the superharmonic tests, this element is the consequence of the nonlinear behavior of the structure itself. Then, it clearly emerges that the oscillations found for the lower dominant frequencies have higher amplitudes when related to the damaged area. Thus, comparing these amplitudes among

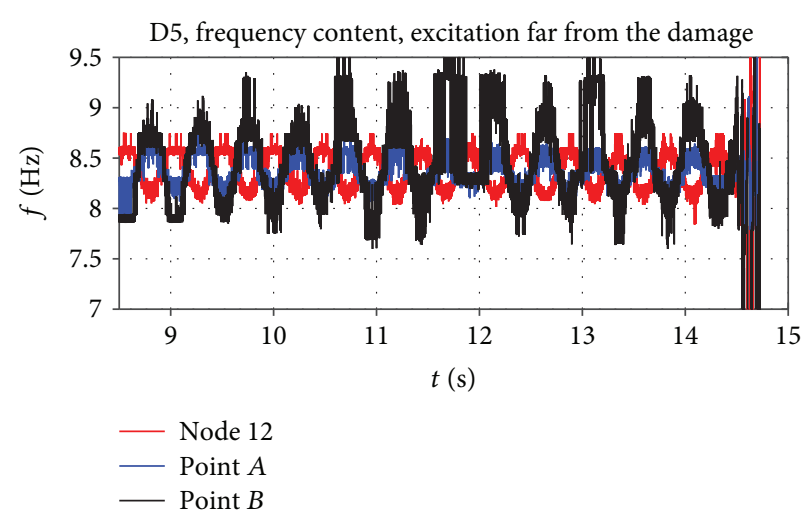

FIgURE 65: D5, maximum frequency, excitation far from the damage.

TABLe 7: D2, excitation near the damage, localization indexes.

\begin{tabular}{lccc}
\hline Index & Node 12 & Point $A$ & Point $B$ \\
\hline$f, \min (\mathrm{Hz})$ & 7.93 & 7.86 & 7.78 \\
$f, \max (\mathrm{Hz})$ & 8.74 & 8.82 & 8.82 \\
$f$, range $(\mathrm{Hz})$ & 0.81 & 0.96 & 1.04 \\
\hline
\end{tabular}

TABLE 8: D2, excitation far from the damage, localization indexes.

\begin{tabular}{lccc}
\hline Index & Node 12 & Point $A$ & Point $B$ \\
\hline$f, \min (\mathrm{Hz})$ & 7.87 & 7.86 & 7.79 \\
$f, \max (\mathrm{Hz})$ & 8.75 & 8.81 & 8.93 \\
$f$, range $(\mathrm{Hz})$ & 0.88 & 0.95 & 1.14 \\
\hline
\end{tabular}

TABLE 9: D3, excitation far from the damage, localization indexes.

\begin{tabular}{lcc}
\hline Index & Point $A$ & Point $B$ \\
\hline$f, \min (\mathrm{Hz})$ & 9.66 & 9.38 \\
$f, \max (\mathrm{Hz})$ & 11.67 & 11.67 \\
$f$, range $(\mathrm{Hz})$ & 2.01 & 2.29 \\
\hline
\end{tabular}

different acceleration elaborations, it is possible to detect and localize the damages. Finally, the nonlinear phenomenon observed, justified by the variation of the local stiffness due to the contact, has shown some remarkable elements. Among them, all the fluctuations identified by the CWT elaborations have exhibited a $2 \mathrm{~Hz}$ oscillation behavior, with higher contributions at the top and the bottom of each one of them. Also, the local effect of damages has resulted stronger than the global nonlinearity of the structure. In this context, the CWT has resulted a powerful tool for the identification of a nonlinear and nonstationary phenomenon.

In order to define a proper quantitative index for the localization, Tables $7-11$ report the maxima and minima frequency values obtained for each elaboration, with the resulting range.

In order to obtain the value reported, proper time intervals have been fixed for the data available in order to include only the dominant frequency oscillations. For all 
TABLE 10: D5, excitation near the damage, localization indexes.

\begin{tabular}{lccc}
\hline Index & Node 12 & Point $A$ & Point $B$ \\
\hline$f, \min (\mathrm{Hz})$ & 7.93 & 7.87 & 7.83 \\
$f, \max (\mathrm{Hz})$ & 8.62 & 8.62 & 8.95 \\
$f$, range $(\mathrm{Hz})$ & 0.69 & 0.75 & 1.12 \\
\hline
\end{tabular}

TABLE 11: D5, excitation far from the damage, localization indexes.

\begin{tabular}{lccc}
\hline Index & Node 12 & Point $A$ & Point $B$ \\
\hline$f, \min (\mathrm{Hz})$ & 7.93 & 7.87 & 7.60 \\
$f, \max (\mathrm{Hz})$ & 8.75 & 8.75 & 9.60 \\
$f$, range $(\mathrm{Hz})$ & 0.82 & 0.88 & 2.00 \\
\hline
\end{tabular}

the cases, the frequency range increases from node 12 to point $B$, so the damage approaches.

\section{Conclusions}

The paper has presented an extension of the nonlinear vibrational methods in a structure reproducing an aeronautical panel, in which three different contact-type damages have been taken into account.

The results presented based on the search for two nonlinear behaviours (superharmonics, variation of the lower frequency of vibration in time) have highlighted the following points in relation to the damage detection procedure:

(i) The nonlinear phenomena here investigated have also emerged with the undamaged structure. Thus, the detection itself by finding these characteristics has not resulted a possibility.

(ii) The localization of the contact damages has been possible through the comparisons of the responses measured. In particular, the variations of the lower frequency of vibration in time have resulted usefulness to detect all the damages analyzed, without requiring the amount of elaboration done for the end defect detection using the superharmonics. Indeed, the amplitude of these variations has resulted sensitivity to the damage location. Moreover, the CWT used to analyze the decay tests data has been identified as a powerful tool for underlining such a nonlinear and nonstationary behaviour.

The numerical procedure executed in order to highlight the presence of suitable nonlinear phenomena has been able to underline effects also found in the experimental tests. Therefore, the contact mechanism model implemented using the local penalty approach has resulted validity for understanding possible nonlinear evidences but needs to be furtherly elaborated in order to ensure true predictions of the analyzed structure. Despite the model assumptions reported in Section 3.3, the nonlinear behavior found in the undamaged structure reveals the requirement of simulations including all the contacts with their whole interferences.
Finally, in order to better explore the nonlinear vibrational methods for applicative cases, further analyses are mandatory: extension of the methods used (step and sine for superharmonics, CWT used for the monitoring of superharmonics in time, and decay tests with more damages of different extensions), new conditions (composites structures, different boundary conditions), and different kinds of damages.

\section{Data Availability}

The data used to support the findings of this study are available from the corresponding author upon request.

\section{Conflicts of Interest}

The authors declare that there are no conflicts of interest regarding the publication of this paper.

\section{Acknowledgments}

Special thanks are due to Mauro Terraneo from Vicoter for his support during the experimental activity and to Dr. Kamal Rezvani for his previous activity on the design, manufacturing, and testing of the reference panel used in this work.

\section{References}

[1] W. J. Staszewski, C. Boller, and G. R. Tomlinson, Eds., Health Monitoring of Aerospace Structures: Smart Sensor Technologies and Signal Processing, Wiley, 2004.

[2] Y. Bar-Cohen, Emerging NDE Technologies and Challenges at the Beginning of the 3rd Millennium-Part I, NDT, 2000.

[3] Y. Bar-Cohen, Emerging NDE Technologies and Challenges at the Beginning of the 3rd Millennium-Part II, NDT, 2000.

[4] T. Stepinski, T. Uhl, and W. Staszewski, Eds., Advanced Structural Damage Detection: from Theory to Engineering Applications, Wiley, 2013.

[5] S. W. Doebling, C. R. Farrar, and M. B. Prime, "A summary review of vibration-based damage identification methods," The Shock and Vibration Digest, vol. 30, no. 2, pp. 91-105, 1998.

[6] J. J. Sinou, "A review of damage detection and health monitoring of mechanical systems from changes in measurements of linear and non-linear vibrations," in Mechanical Vibrations: Measurement, Effects and Control, pp. 643-702, Nova Science Publishers, Inc, 2009.

[7] P. Cawley and R. D. Adams, "The location of defects in structures from measurements of natural frequencies," The Journal of Strain Analysis for Engineering Design, vol. 14, no. 2, pp. 49-57, 1979.

[8] S. L. Tsyfansky and V. I. Beresnevich, "Non-linear vibration method for detection of fatigue cracks in aircraft wings," Journal of Sound and Vibration, vol. 236, no. 1, pp. 49-60, 2000.

[9] K. Rezvani, Vibration-based damage identification techniques, [Ph.D. thesis], Politecnico di Milano, 2015.

[10] M. Gordan, H. A. Razak, Z. Ismail, and K. Ghaedi, "Recent developments in damage identification of structures using data mining," Latin American Journal of Solids and Structures, vol. 14, no. 13, pp. 2373-2401, 2017. 
[11] S. A. Neild, Using non-linear vibration techniques to detect damage in concrete bridges, [Ph.D. thesis], University of Oxford, 2001.

[12] S. O. Vismara, Non-linear spacecraft component parameters identification based on experimental results and finite element model updating, [M.S. thesis], Politecnico di Milano, 2015.

[13] J. N. Sundermeyer and R. L. Weaver, "On crack identification and characterization in a beam by non-linear vibration analysis," Journal of Sound and Vibration, vol. 183, no. 5, pp. 857871, 1995.

[14] A. Rytter, Vibrational based inspection of civil engineering structures, [Ph.D. thesis], Department of Building Technology and Structural Engineering, Aalborg University, 1993.

[15] V. Volterra, Theory of Functionals and of Integral and IntegroDifferential Equations, Dover Publications, 1959.

[16] D. M. Storer, Dynamic analysis of non-linear structures using higher order frequency response functions, [Ph.D. thesis], University of Manchester, 1991.

[17] R. Ruotolo, C. Surace, P. Crespo, and D. Storer, "Harmonic analysis of the vibrations of a cantilevered beam with a closing crack," Computers \& Structures, vol. 61, no. 6, pp. 1057-1074, 1996.

[18] M. Carminati, Damage detection using nonlinear vibrations, [M.S. thesis], Politecnico di Milano, 2016.

[19] "MSC nastran 2013 dynamic analysis user's guide, MSC software," https://simcompanion.mscsoftware.com/infocenter/ index? page $=$ content $\&$ id $=$ DOC10354\&actp $=$ RSS .

[20] C. K. Chui, Wavelet Analysis and Its Applications-I: an Introduction to Wavelets, Academic Press, 1992.

[21] C. K. Chui, Wavelet Analysis and Its Applications-II: a Tutorial in Theory and Applications, Academic Press, 1992.

[22] M. Rucka and K. Wilde, "Application of continuous wavelet transform in vibration based damage detection method for beams and plates," Journal of Sound and Vibration, vol. 297, no. 3-5, pp. 536-550, 2006.

[23] M. C. C. Bampton and R. R. Craig Jr., "Coupling of substructures for dynamic analyses," AIAA Journal, vol. 6, no. 7, pp. 1313-1319, 1968.

[24] K. Roughen, J. Huang, D. Hammerand, D. Stuewe, and S. Hertz, "Efficient simulation of structural dynamic systems with discrete nonlinearities," in 52nd AIAA/ASME/ASCE/ AHS/ASC Structures, Structural Dynamics and Materials Conference, pp. 1-7, Denver, CO, USA, 2011.

[25] S. Loutridis, E. Douka, and L. J. Hadjileontiadis, "Forced vibration behaviour and crack detection of cracked beams using instantaneous frequency," NDT \& E International, vol. 38, no. 5, pp. 411-419, 2005. 


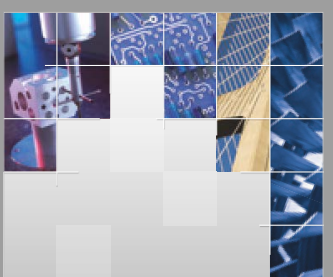

\section{Enfincering}
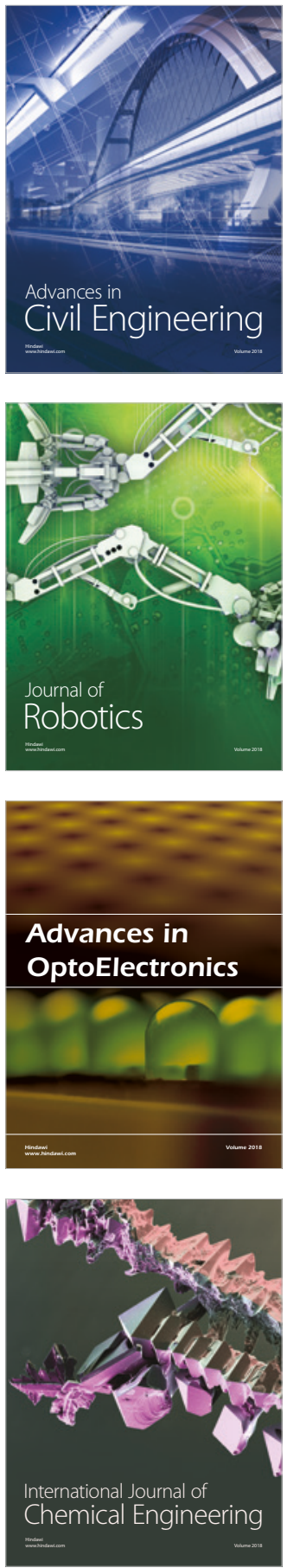

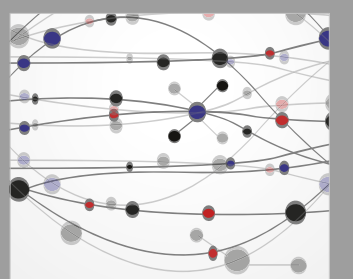

\section{Rotating \\ Machinery}

The Scientific World Journal

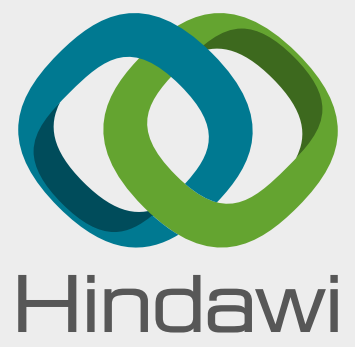

Submit your manuscripts at

www.hindawi.com
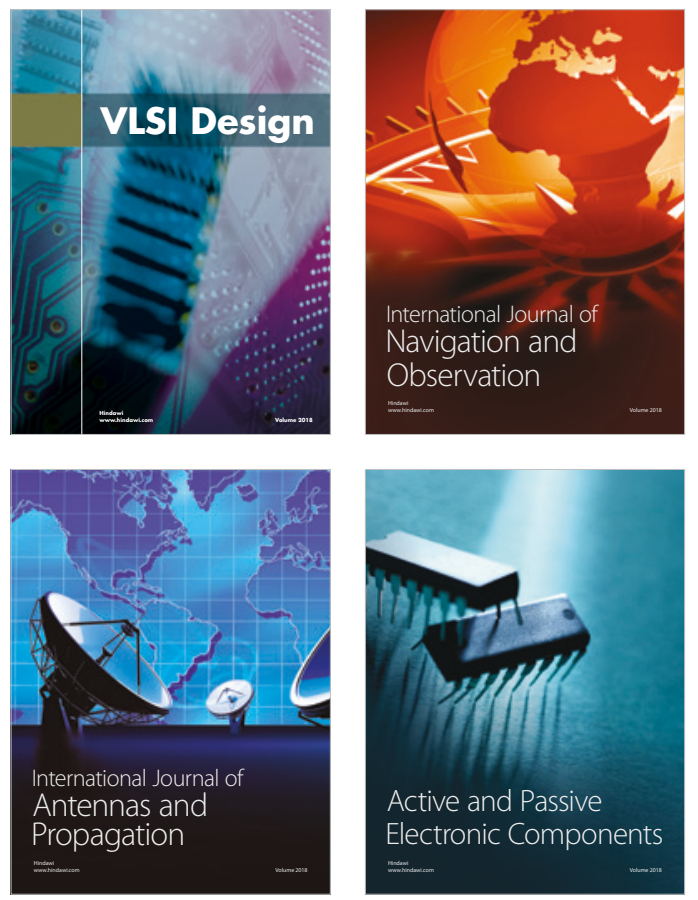
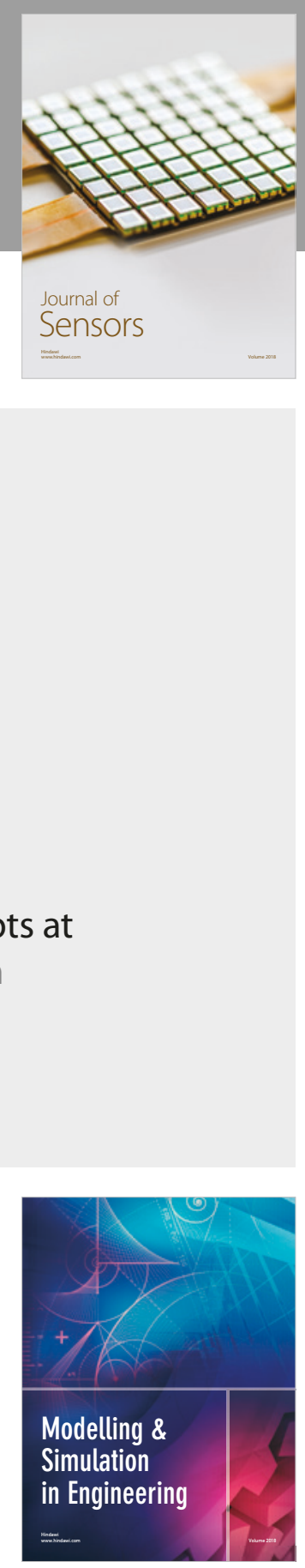

\section{Advances \\ Multimedia}
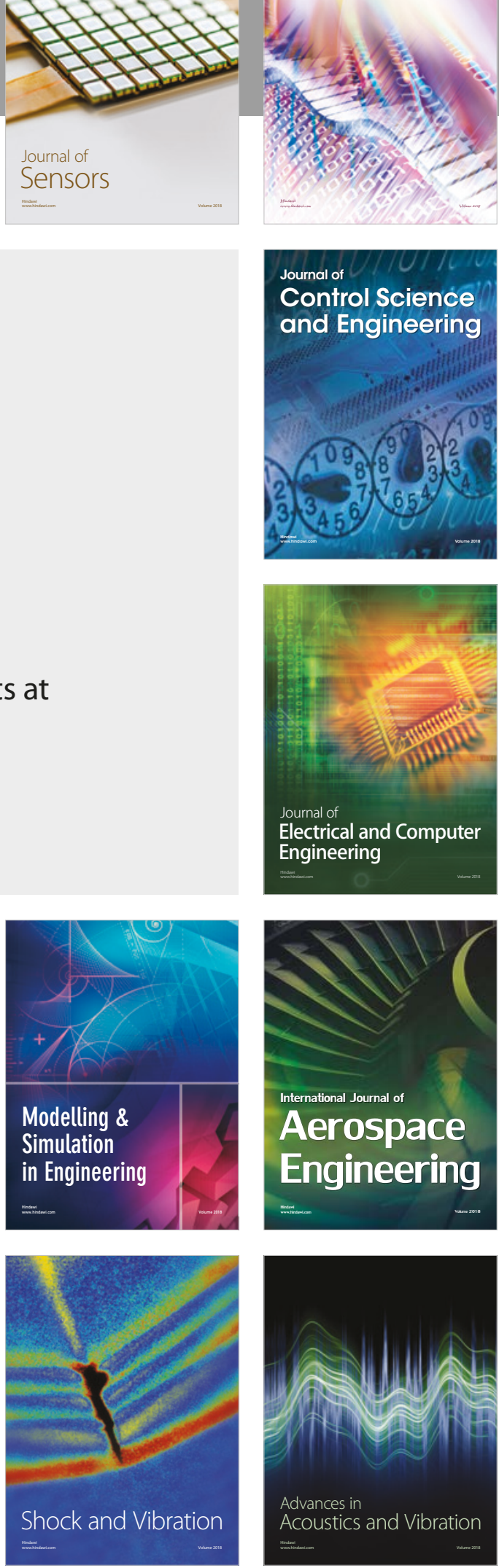